Illinois State University

ISU ReD: Research and eData

Theses and Dissertations

$10-23-2017$

\title{
Intercultural Accommodation: Accommodating Communication To People Of Different Groups
}

Marcus M. Gruwell

Illinois State University, marcus.gruwell@yahoo.com

Follow this and additional works at: https://ir.library.illinoisstate.edu/etd

Part of the Communication Commons

\section{Recommended Citation}

Gruwell, Marcus M., "Intercultural Accommodation: Accommodating Communication To People Of Different Groups" (2017). Theses and Dissertations. 859.

https://ir.library.illinoisstate.edu/etd/859

This Thesis is brought to you for free and open access by ISU ReD: Research and eData. It has been accepted for inclusion in Theses and Dissertations by an authorized administrator of ISU ReD: Research and eData. For more information, please contact ISUReD@ilstu.edu. 


\title{
INTERCULTURAL ACCOMMODATION: ACCOMMODATING COMMUNICATION TO PEOPLE OF DIFFERENT GROUPS
}

\author{
Marcus M. Gruwell
}

96 Pages

The current study attempts to address the widening division of race and communication due to large demographic changes in Western countries like the United States. Applying Communication Accommodation Theory and prior studies from Postcolonialism research, this researcher intends to develop a more concrete understanding as to why people will change their speaking behaviors when encountering different ethnic groups. Concepts of postcolonial mentality and changes in speaking behaviors will create a clearer explanation as to why people act in certain ways towards different people

KEYWORDS: Race; Communication Accommodation Theory 
INTERCULTURAL ACCOMMODATION: ACCOMMODATING COMMUNICATION TO

PEOPLE OF DIFFERENT GROUPS

MARCUS M. GRUWELL

A Thesis Submitted in Partial Fulfillment of the Requirements for the Degree of MASTER OF SCIENCE

School of Communication

ILLINOIS STATE UNIVERSITY

2018 
(C) 2018 Marcus M. Gruwell 
INTERCULTURAL ACCOMMODATION: ACCOMMODATING COMMUNICATION TO

PEOPLE OF DIFFERENT GROUPS

MARCUS M. GRUWELL

COMMITTEE MEMBERS:

John R. Baldwin, Chair

Kevin R. Meyer

Jeffrey L. Courtright 


\section{ACKNOWLEDGMENTS}

I would like to thank Dr. Baldwin for helping me get this far with his careful guidance and patience during this process. I would also like to thank the rest of my committee, Dr. Meyer and Dr. Courtright in their assistance in helping me progress in my thesis. Lastly, I would like to thank my family for their support throughout my life.

I would also like to thank my girlfriend, Ka Kei Cheong, for her support throughout my time at ISU. I would also like to thank everyone who contributed in being participants with the study, this could not have been accomplished without you. Finally, I would like to acknowledge my late dog, Joe, who passed away during the final days of my thesis completion.

M. M. G. 


\section{CONTENTS}

\section{Page}

ACKNOWLEDGMENTS

CONTENTS

CHAPTER I: INTRODUCTION 1

CHAPTER II: LITERATURE REVIEW 4

Postcolonialism Definition/Description $\quad 4$

Causes and Effects of Colonialism $\quad 9$

$\begin{array}{ll}\text { Manifestations of Postcolonialism } & 10\end{array}$

$\begin{array}{ll}\text { Race } & 10\end{array}$

$\begin{array}{ll}\text { Sex and Gender } & 13\end{array}$

$\begin{array}{ll}\text { Caste Systems in Colonized Societies } & 15\end{array}$

$\begin{array}{ll}\text { Communication and Colonialism } & 19\end{array}$

$\begin{array}{ll}\text { Media } & 19\end{array}$

Interpersonal Communication between Races $\quad 22$

$\begin{array}{ll}\text { Communication Accommodation Theory } & 23\end{array}$

$\begin{array}{ll}\text { Convergence and Divergence } & 24\end{array}$

$\begin{array}{ll}\text { When we should converge and diverge } & 26\end{array}$

$\begin{array}{ll}\text { The Present Study } & 27\end{array}$

$\begin{array}{ll}\text { Conclusion } & 29\end{array}$

$\begin{array}{ll}\text { CHAPTER III: METHODS } & 31\end{array}$

$\begin{array}{ll}\text { Participants } & 31\end{array}$

$\begin{array}{ll}\text { Data Collection } & 32\end{array}$ 
Conclusion

Media

Stereotypes of Ethnic Groups $\quad 42$

$\begin{array}{ll}\text { Positive views } & 44\end{array}$

Different Ways of Communicating Based on Race 45

Slight Changes of Communication $\quad 45$

$\begin{array}{ll}\text { No changes } & 46\end{array}$

$\begin{array}{ll}\text { Changes but not Specifying } & 47\end{array}$

Changes in Verbal Communication 48

$\begin{array}{lr}\text { Paralinguistic level } & 48\end{array}$

$\begin{array}{ll}\text { Phonology } & 49\end{array}$

$\begin{array}{ll}\text { Rate of speech } & 51\end{array}$ 
$\begin{array}{ll}\text { Semantic level } & 51\end{array}$

$\begin{array}{ll}\text { Syntactic level } & 54\end{array}$

$\begin{array}{lr}\text { Pragmatic level } & 54\end{array}$

Changes in Nonverbal Communication $\quad 55$

$\begin{array}{ll}\text { Conversational Patterns } & 56\end{array}$

Topic choice and turn-taking $\quad 56$

Reasons for Change $\quad 56$

$\begin{array}{ll}\text { Communication Clarity } & 57\end{array}$

$\begin{array}{ll}\text { Impression Management } & 58\end{array}$

$\begin{array}{lr}\text { Conversation Quality } & 60\end{array}$

$\begin{array}{ll}\text { Comfort and enjoyment } & 60\end{array}$

Building Connections with the Other Speaker $\quad 62$

$\begin{array}{ll}\text { Conclusion } & 62\end{array}$

$\begin{array}{ll}\text { CHAPTER V: DISCUSSION } & 64\end{array}$

$\begin{array}{ll}\text { Summary of Findings } & 65\end{array}$

$\begin{array}{ll}\text { Implications } & 69\end{array}$

$\begin{array}{ll}\text { Theoretical Implications } & 69\end{array}$

$\begin{array}{ll}\text { Postcolonial theory } & 70\end{array}$

$\begin{array}{ll}\text { Communication Accommodation Theory } & 74\end{array}$

Strengths, Limitations and Directions for Future Research 76

$\begin{array}{ll}\text { Strengths and Limitations } & 76\end{array}$

$\begin{array}{ll}\text { Future Research } & 79\end{array}$ 
Summary

REFERENCES 


\section{CHAPTER I: INTRODUCTION}

According to the United States Census Bureau, over half of American children will be members of a minority group by 2020 while half of the population of the United States will eventually consist of minorities by 2044 (Colby \& Ortman, 2015). According to Pew Research Center, Hispanic and Asian populations in the United States have continued to increase with the White and Black populations increasing at a slower pace (Cohn \& Caumont, 2016). According to the United States Census Bureau (2015), the White population of the country is set to be a minority, leaving no major racial group making up a majority of the population. Such statistics will likely bring into question how the demographic changes will affect society. After all, race is a socially constructed concept to differentiate someone else simply by the pigmentation of one's skin. In a multicultural country like the United States, however, these foreseeable changes can be daunting to some. Changes in these growing minority populations could likely complicate administrations and rules on properly accommodating them in the workforce and schools. The increasing issue with racial ties in the United States can make adjusting to these changes difficult. According to Pew Research (2016), most Americans believe that racial equality has yet to be achieved. Krysan and Moberg (2016) add that racial attitudes from White respondents on racial inequality say that Whites were less likely to push forward on improving equality in the past, meaning that some Whites in power still have not moved in the direction of providing equal treatment for all racial groups. Past research regarding racial attitudes towards other ethnic groups reveals the complexity and sensitivity of the current issues resonating within modern societies (Entman \& Rojecki, 2000). According to the United States Census Bureau (2015), nonHispanic Whites in the United States dropped from 63 to 61 percent from 2010 to 2015, allowing 
for other racial groups to rise creating a vast amount of uncertainty of how to prepare of such change.

These statistics reveal that, despite the change in racial demographics, increases in migration of non-White ethnic groups can polarize attitudes among homogenous societies (Tuch, 1987). Interestingly, in the United States, White Democrats are more likely than White Republicans to admit that Blacks have less equal treatment than other racial groups (Pew Research, 2016). Politics have hence also played a large role in racial equality in the United States. Western media have also played an integral part in racial equality because media coverage on different races has had a large impact on viewers and their overall perceptions of different racial groups regarding how these groups should be treated (Sommers, Apfelbaum, Dukes, Toosi, \& Wang, 2006). Reports addressing racial equality have demonstrated to viewers how to identify people of other races and what stereotypes may be articulated when conversing with racially different speakers.

The significance of this study is that it may help us better understand why a person's speaking behavior changes in conversing with others that are racially or ethnically different. I use a qualitative approach for my thesis project and have collected data through online surveys to better understand why people may change their speaking behavior towards people of different racial groups. I want to find out whether speakers become more or less accommodative when speaking with others and what tendencies they have or what influences altered their decision regarding how they speak with others. I also hope to understand if people think that current media have created preconceived notions on how speakers may change the way they speak with people from other groups based on negative coverage and created stereotypical perceptions of other identity groups in the United States, thus altering perceptions. 
My literature review will focus on how colonialism affects and possibly hinders communication with people of different races and how other racial identity groups are treated in a postcolonial world. I will go into the history of colonialism and the lingering effects that stem from it in the form of postcolonialism. Sex will also be touched on to better understand how equality works with men and women of color. Finally, Communication Accommodation Theory (CAT) will be introduced to explain how and why people change their speaking and if they are more likely to converge or diverge to people of different racial groups. 


\section{CHAPTER II: LITERATURE REVIEW}

\section{Postcolonialism Definition/Description}

Looking at the division of race across the world, this thesis will address postcolonialism and how the lingering effect of colonialism has been only partially addressed in face-to-face communication research. To understand postcolonialism, it is important to know about colonialism and what brought about the global takeover and control of most of Earth's inhabitants by previous imperialistic, European nations. Dirks (1992) best describes colonialism as a "cultural project of control" (p. 5). In short, colonialism can be summarized as the foreign takeover of another country, establishing laws, cultures and creating unfair mistreatment of nonWhite inhabitants. Dirks argues that colonizers' increasing desire to categorize races of people based on racial identity has led to the current racial classification system. The permanent effects of colonialism from history have created one group establishing power over others, benefitting a colonial populace and thus creating an unfair balance of overall prosperity (Marker, 2003). In modern times, there still exist social barriers that separate racial groups because of the past actions mentioned from colonialism and the devastating effects that have since remained.

The residue of colonialism has revealed that existing social barriers have not only separated races but created a natural imbalance of power, which can be seen as a norm in Western society. The misconception of other races because of the actions of European colonizers has not only become a norm but a dangerous habit by which dominant cultural members continue to demonize non-Whites. The encouragement of adaption to a majority culture is demonstrated in Western society where non-White ethnic groups are recommended to conform to a new culture. Media are seen to influence how ethnic groups may be treated in a postcolonial society. The link to postcolonialism and studying in the United States is that bringing people of 
different ethnic groups together, such as occurring at universities, can have ramifications such as people not being exposed to different groups that could lead to changes in speaking behaviors. For example, Whites who come from small homogenous towns and entering universities might carry racial attitudes towards other ethnic groups that may have been previously held because of lack of exposure to different groups of people. Having these attitudes could then inform perceptions of Blacks and others ethnic groups due to postcolonial residue of linking Blacks and other minority groups to inferiority.

In terms of internal colonization, the migration of forced Blacks into mostly native occupied lands likely created the negative mentality toward Blacks, particularly in Latin American countries along with the United States. The unfavorable view of natives in the eyes of White colonizers transcended into a view of seeing natives as being poor and not intelligent, thus the $21^{\text {st }}$ century view of the two ethnic groups best represents the actions of colonization and how people may apply these postcolonial attitudes to non-White speakers. Examining participants’ views may reveal how speakers look at others through a postcolonial lens because of the actions and labels placed upon Indigenous people and Blacks. A postcolonial lens can reveal behaviors like treating people from other races differently because of the already negative perception one has about certain ethnic groups. Postcolonialism can then be seen in the processes that occur in certain interactions, from stereotyping to treating people of other ethnic groups differently because of historic racism.

Although changes in speaking behaviors to other ethnic groups are not bad, the changes can lead one to have a negative perception of a certain member of a different ethnic group. The very belief that certain ethnic groups are expected to act a certain way because of instances of historic changes could reflect a colonial mindset. Self-identification is also important in a 
postcolonial world because it makes those aware of their own racial identity and sense of belonging in a similar group while also recognizing the physical differences of others. Selfidentifying in terms of one's race could provide an understanding as to why people in some groups may look at those in other groups differently. The term "race" is then important for not only individual recognition but understanding self-identity inside a homogenous group.

While it appears that countries have tried to address the cultural and racial divides that colonialism brought, many negative aspects of colonialism remain in numerous countries ruled by democracy. Media organizations that stereotype due to colonial habits have still objectified other ethnic groups despite advancement in face-to-face communication between different groups. Alhassan and Chakravartty (2011) report that colonialism and current media create issues that have still not been addressed by state leadership. Much of Western media still cannot relate to nations and people outside of the Western world, thus the reason for created stereotypes.

European colonist instilled methods of control, subjecting indigenous subjects to unfair treatment because of ethnic differences. Colonialism itself is the takeover of another country by imperialistic and often European methods of control; essentially, it is a state that is established by foreign rule (Stuchtey, 2011). Such imperialistic movements in past times have often brought about political change, introducing "civilized" rule while simultaneously extorting natural resources and leaving countries in a caste-like system. While colonization is seen more in a negative light due to the atrocities committed under the name, colonialism has also led to the introduction of important goods like medicine and technology.

Postcolonialism challenges European colonial order in the poorest developing nations, where colonialism's strongest effects have lingered longest. Ivison (2015) describes colonialism as a destructive time and is the product of the West's colonial actions outside of Europe. In 
present times, colonialism can often be associated with negative terms due to its effects that continue to resonate and affect people across the world, particularly in poorer postcolonial countries. Loomba (2015) summarizes colonialism as “the conquest and control of other people's lands and goods" (p. 20). Genocide and warfare were two tactics used that created the greatest number of casualties, particularly in the Americas where indigenous people are still suffering. As result of little research being done in this field, many poorer and often non-White citizens of societies continue to suffer in terms of poverty and racial discrimination from their White counterparts in western and postcolonial countries due to colonialism.

While postcolonialism promotes freedom from foreign control, old, European imperialist mentalities linger in poorer countries in South America and Africa. Said (1986) describes the type of colonial power Europeans had over their non-White subjects as ruling over while profiting from far-away countries. While the power of Europeans in postcolonial countries has lessened, there are still uneven amounts of governance exerting unfair power over non-White citizens. Racial issues still remain in countries in Latin America as the problems are widely ignored and denied by Latin officials (Pitt-Rivers, 1967). Living and benefiting in a postcolonial society where the rules are made in favor of the rich and powerful, it is easy to dismiss acts of discrimination against a poorer, non-White populace. Colonizers' actions have destabilized multiple societies around the globe and have created racial division through "territorial segregation," leaving indigenous subjects as the victims of European action (Mamdani 1996). Often, the colonized subjects' issues were widely ignored for much of the colonial period. Shome and Hedge (2002) discuss how attempts of the colonized to break free from colonial chains were often met with resistance. Shome and Hedge report that: 
As a result of the depletion of raw materials and resources by former colonial powers, as well as previous suppression of any attempts by the colonized to produce a selfgoverning political structure, many of the emerging nation-states lacked, and consequently had to build, the infrastructure necessary to sustain a "civil society." (pp. 253-254).

The drain of critical resources from colonial territories is displayed presently because many postcolonial countries' inhabitants remain in poor state.

Across the world, millions of colonial subjects suffered from poverty and death because of the neglect and mistreatment of European colonizers. Immense effects of inequality are the cause of colonizers and the harsh system that was bestowed upon non-White subjects (Acemoglu \& Robinson, 2017). Future descendants were left in poor conditions because of non-White groups being cast into years of forced assimilation by colonizers. Native Americans, Africans, and Asians were the victims that suffered because Europeans believed that these races did not possess the tools to sustain the same lifestyle as them, thus the creation of colonization using systematic discrimination and torture was justified (Césaire, 2000). Christianity was implemented in order to "civilize" colonial Black and Native subjects. This ties in with the current argument because many perceptions were developed of groups of people that were colonized in the past are still held to the present day through discrimination and racism. However, some nations were already advancing prior to colonization. Many African economies, for example, were already advancing in many areas (Settles, 1996). Countries and empires that became colonized hence could have likely advanced and grown independently without colonialism. 


\section{Causes and Effects of Colonialism}

Colonial oppression continues to have problematic effects on non-White people due to racial differentiation and unbalanced wealth. Eighty-eight percent of Blacks and 7 in 10 Hispanics believe that changes are needed for Blacks to have equal rights with Whites, compared with 53\% of Whites in the United States (Stepler, 2016). There are 38\% of Whites, however, that believed major changes have been made while about 4 in 10 Blacks (43\%) are doubtful that the country will ever make the changes needed for Blacks to have equal rights with their White counterparts while only $11 \%$ of Whites and $17 \%$ of Hispanics share this view (Stepler, 2016). In conclusion to these studies, the results show the demographic gap that resonates within countries; however, more research is needed to properly establish these points thoroughly.

The effects of colonialism have hence thrown many racial groups of non-White people into poverty where access to better resources comes with limitations. Many regions of the world lack overall prosperity because of the actions of European colonists (McClintock, 1992). Systematic discrimination from colonialism prevented Blacks and Native Americans from advancing and achieving equal status to Whites and other racial groups. Minorities that are often discriminated against due to cultural and colonial policies are often Blacks (Dixon \& Rosenbaum, 2004). For example, Black drivers are more likely to be pulled over by police than White drivers in the United States (Giles, Linz, Bonilla, \& Gomez, 2012). The issues can be linked to create the perception that Blacks may cause trouble. The sort of behavior than may be a result of colonialism as Blacks in colonized territories were considered inferior and subordinate to Whites. Looking at the actions of colonization through an anti-imperialistic lens is then necessary to have a better understanding of postcolonial effects.

Many Western, post-imperialistic nations are still benefiting from resources stolen during 
the colonial era while many postcolonial countries still suffer. Colonialism resulted in large part because of countries like the United Kingdom and Spain sailing out to new territories, where Natives would be put under control and lose most of their freedom and resources (Young, 2016). These postcolonial nations that would eventually become independent would still struggle with poverty, particularly in Africa and Latin America. These colonized territories were then left as underdeveloped, so-called "third-world" nations.

\section{Manifestations of Postcolonialism}

\section{Race}

The problem of colonialism extends to the present day as non-White groups, whose ancestors were once ruled by European colonizers, continue to face discrimination. Despite the good that may have stemmed from colonialism, Lange and Dawson (2009) assert that

colonialism itself was bad for its colonies' nonwhite populace. They state several problems with colonialism: “1) By constructing oppositional identities, 2) institutionalizing an ethnic-based division of labor, 3) creating ethnic-based hierarchies, 4) introducing foreign populations, 5) imposing arbitrary political borders, 6) promoting despotic forms of rule, and 7)

Institutionalizing ineffective states" (p. 786). The connection between the United States and other postcolonial countries is that the sort of Western imperialistic methods used were similar in treatment of non-White groups. Colonialism, however, has had many different changes and effects on countries around the world. Postcolonial Macau, for example, is much different than countries like Somalia, due to economic wealth. Prior to European imperialism, some countries were more advanced than others, which then explains the different outcomes of previous postcolonial territories. 
Postcolonialism continues to play a negative role for the non-White populace because the after-effects of colonialism advance into the present, physically damaging the non-White populations mentally and psychologically. Shome and Hedge (2002) note that colonialism has always been an avoidable subject in discussion of actions of European exploration. An example of past racial classifications and discrimination lies in Brazil, where a mass influx of European immigrants settled in the country while Blacks and Natives historically were slaves, creating racist practices that continue well into the $21^{\text {st }}$ century as White Brazilians enjoy a better way of living than non-White Brazilians (Telles \& Paixão, 2015). People of color in postcolonial societies seem to suffer the greatest setback in terms of status and wealth because of postimperialistic methods that worked in favor of the colonist. Hall (2007) best describes how Blacks in the Caribbean continue to struggle due to colonial rules created against them leaving most Blacks to live in almost infant state-like societies. Countries outside of Western Europe are often considered "third world." Mohanty, Russo, and Torres (1991) best summarize term "third world" "as being defined through geographical as well as particular sociohistorical conjunctures" (p. 2). This term, however, can have racist connotations, as third world is suited with nations that are usually non-White.

The most intriguing aspect from postcolonial countries is the presence of people of mixed descent, usually stemming from "race mixing," due to colonial desire for hybridity. The identity of these-mixed race people brings about current conceptions that define these people's race or ethnicity. However, Hall (2007) argues that the term "hybridity" should not be used due to its connotation to globalization, which then treats cultures like businesses. In many Latin postcolonial countries, much of a population may even be made up of mixed races, often from the colonizer and the native colonized. White (1999) best summarized miscegenation as races of 
people interbreeding while creating the elimination of their own culture. Miscegenation was popular in colonial countries due to European settlers and creoles in charge of slaves believing in the necessity to help propagate more slaves (De Almeida, 2002). Presently, the mixed-race population has likely grown due to popularity of interracial marriages, or at least interracial sexual union. Importantly, postcolonial structures are still present in many countries affecting poorer non-White people, as Strongman (2014) argues that "the lived realities of starving, wartorn and displaced peoples, throw into question the ambiguities of the modernism within postcolonialism that may hinder or produce, but also positively effect, change" (p. 1347). As mentioned, colonialism did bring law and government that may have otherwise not been present with pre-colonized people. While Hall states that there was resistance to colonial rule, the growing White populace in colonial countries held little hope for change to the colonized nonWhite people. Postcolonialism explains the cultural racial divides and changes that were brought from European settlers and the effects that continue to hinder non-White groups.

Africans sent into slavery by the millions seem best to illustrate the actions of colonialism and state of many poorer postcolonial nations with Black majorities presently. Many Africans still live in poverty and face other forms of discrimination created by unfair laws during colonial rule. The Spanish colonial policy put in place in Latin America had created racial division to distract non-White subjects from European subjugation (Fiehrer, 1979). While many Africans in the colonial period would be able to become free men of color, there still are limitations and restrictions that hinder Africans across the new world that continue well into the $21^{\text {st }}$ century.

The treatment of other races in cast systems still functions around the world. Hall (2007) asserts that little power given to non-White people has led to the issues regarding their status today, such as "the silencing of the Black and Brown speaking body', which has enabled the rise 
of White colonizers to speak on their behalf' (p. 10). The forced silenced of the non-White populace thus translates smoothly into the $21^{\text {st }}$ century of poorer postcolonial countries. The growth of Non-White populations in countries affected by colonialism will likely create changes in controversial policies made by higher positions of power previously held by White officials. Bhambra (2007) describes the changes brought by Western imperialism as changing moderately while introducing Western traditions to non-White people such as globalization in the form of changing the culture of Non-Westerners. When describing reasons for European colonialism, Bhambra presents extreme eurocentrism as the reason as to why Western imperialists executed harsh treatment against non-White colonial subjects.

\section{Sex and Gender}

The effects of colonialism and transition into postcolonialism have likely created greater suffering for women than men. European colonists' strong desire for physical characteristics of African women created a Eurocentric desire to mentally conquer them. (Ruiz, 2012). Colonial rule and discriminatory practices likely caused Black women to be widely ignored in Western advertisements. In the United States, women of color still are vastly underrepresented in beauty advertisements and other sections in the media, thus creating a narrow and racially bound cultural view of beauty (Frith, Cheng, \& Shaw, 2004). This view of beauty has since been associated with wanting to maintain a whiter skin color, particularly among women of color who may feel the need to beautify themselves with whitening cosmetics. The issues stated thus create an image of identity-inferiority likely stemming from Colonialism. Often in beauty advertisements, men and women of color are expected to possess White characteristics, thus eliminating any chance for people of color to display their own cultural beauty (Cortese, 1999). Examining postcolonial outcomes can then expose the current postcolonial problems that women 
of color in westernized societies continue to face, for example, having to assimilate into a culture that may not serve non-White women. Specifically focusing on Africans, Ruiz (2012) discusses issues regarding White imperialism and Black feminism asserting that White male imperialism still affects Black female beauty, in part through praise of the White female body. A racial view of beauty has since likely risen due to colonial desire to have mostly White models, deeming other non-White women as not attractive.

The rise of women's rights and feminism in postcolonial countries has likely given power to women to oppose colonial, male-dominated control. Feminism in male-dominated societies has made large strides to oppose stereotypical roles (Calas \& Smircich, 1996). Women of different ethnicities and religion in homogenous societies can be easily stereotyped because of the postcolonial attitudes that resonate that often ignore different ethnic groups and culture. Golnaraghi and Mills (2013) explore postcolonialism by analyzing Arab and Western women and discussing how people of different religions and race can still seem to be imposing upon each other and causing a threat to Western civilization due to fear of physical differences. The study revealed how western dominance can sometimes reduce women to silence. In other cases, colonialism changed the existing structure of sex and gender roles. Native Americans suffered the worst from colonial and postcolonial periods because many natives still have shown to exert little to no power. European colonialism subjected Native American women to having insignificant roles and had Native American men own more land due to resource distribution by settlers in colonial times and allowing only men to receive gifts like horses (Klein, 1983).

Syed (2007) argues how ethnically different women are at a disadvantage and are unable to reach to full economic opportunities that their White female counterparts receive. "Feminism in a postcolonial frame begins with the situation of the ordinary woman in a particular place, 
while also thinking her situation through in relation to broader issues to give her the more powerful basis of collectivity” (Mishra, 2013, p. 130). Reducing male dominance in postcolonial countries has since given women the freedom to act and think more independently and to not be held back by a colonial and patriarchal system created by males. However, Tyagi (2014) argues, "Postcolonialism and feminism have come to share a tense relationship, as some feminist critics point out that postcolonial theory is a male-centered field that has not only excluded the concerns of women, but also exploited them" (p. 46). Many men may view the independence by feminists as a threating attempt to undermine a Westernized patriarchal system that has prevailed and has empowered men for centuries.

\section{Caste Systems in Colonized Societies}

The invention of colonial, European-made caste systems continues to have detrimental effects on descendants of the colonized such as indigenous people, Africans, and mixed-race people living in a postcolonial world. In fact, a strong Western perspective on postcolonialism ignores the very colonial rules created in Spanish and Portuguese colonies as the non-White populace continues to suffer while the colonial mentalities from the colonizers' rule remain unchanged. Spanish and Portuguese colonial empires used ideas like racial difference and patriarchy to conquer claimed territories (Salvatore, 2010). The creation of colonialism and the exploitation of non-White peoples have since created a caste system where the colonizer population can thrive more so than the non-White descendants of the colonized, particularly in Latin American countries. The current issues in postcolonial countries strongly resonate with those of Hispanic and African descent because of unfair treatment. Salvatore (2010) notes how interpersonal communication between indigenous people and the upper, often whiter class has lacked research mostly because of the social barriers from colonialism between groups. 
Noticeably, colonizers' actions against native subjects are clearly relevant today, as Salvatore argues that "the peoples inhabiting the interior, or the backlands of these modern nations were racialized and construed as incapable of self-government and civilized sociability" (p. 341). The assumptions and stereotypes have hence likely affected North American neighbors like the United States and Canada with growing minority populations.

Racial systems from colonialism have shown that ethnic apprehension often occurs in a postcolonial world due to polices that favor the descendants of colonizers. Citizens that belong to a different race other than White were in part placed into categories by colonists to separate people based on different skin pigmentation (Gunew, 1997). Many non-White people that inhabit westernized nations likely face the problem of being least benefited by policies that may favor a White, homogenous society.

Blacks in colonial systems have suffered because of slavery and mistreatment from their White counterparts during colonial periods, which has greatly affected their struggle for equality in the present. Africans were identified through a colonizer's lens in negative ways: African Women, for example, are dramatized as being problematic in western societies because of the negative image that was cast upon them from colonizers (Plasa, 2000). In many cases, Blacks suffer the greatest amounts of discrimination from other racial groups due in part to the colonial caste system that was emplaced by colonizers and the limited amount of power Blacks were given. In the United States, Blacks are more likely than Whites to see racial discrimination (70\% vs. $36 \%$ ), where lower quality schools ( $75 \%$ vs. $53 \%$ ) and lack of jobs (66\% vs. $45 \%)$ are major reasons that why African Americans may have a more difficult time to get ahead than Whites (Pew Research, 2016). Blacks in countries like the United States, thus, still suffer because of 
colonial mistreatment in past centuries and the residue of colonialism that affected countries like the United States.

Another colonial policy-like caste system was Apartheid in South Africa, where Blacks were largely segregated and forced to live in a Western world while receiving unfair treatment by colonizers. This sort of treatment has likely since transcended into the current postcolonial mindsets of all races of people because Apartheid housing created in South Africa was mostly segregated during Apartheid. Christopher (1983) argues that "the influence of the rural settlement frontier and the Afrikaner nation on the origins of this development is subordinate to the major input of English colonialism” (p. 148). Separation between racial groups during colonial rule in South Africa still likely resonates with its citizens. The rules created in the Apartheid policy reveal that, in postcolonial Africa, Black Africans were less likely to receive the same treatment compared to Whites (Mountain, 2003). The colonial rules, while no longer in existence, still show how much of the whiter people of a postcolonial country still benefit in terms of better, more prosperous lives, unlike their Black neighbors. Racial classifications and categories created by colonizers have not only benefited the descendants of colonizers but also deepened the racial divide of ethnically different, non-White people across the world.

Christopher (1983) asserts, "While segregation was only informal, attempts were made through legislation, prosperity trusts and bylaw regulations to convert the segregated city into the more structurally formal apartheid city" (p. 147). Many of the actions taken by European colonizers have hence strongly affected the lives of Blacks in countries like South Africa because of the favor towards colonial Whites during times like Apartheid.

Many Blacks and Native Americans in colonial times by far suffered the most in terms of mistreatment in the forms of resource loss, genocide, and land consumption. European 
justification of the treatment of many non-White inhabitants of soon to be colonized territories was to bring civilization and religion to people considered primitive and demon-like (Watson, 2009). The violence committed during the colonization and conquest by Europeans forever impacted the lives of Native Americans, drastically reducing Native populations, leaving them little political power. Reports detail a mass genocide created by European colonists (Jaimes, 1992). Jaimes (1992) reports, "Data revealed that the actual rate of extermination pertaining to Native North America during the period of conquest as having been to 98 to 99 percent overall” (p. 7). It can be understood that in many countries in the Americas dominated by European power, natives had little resistance to their cultural demise through colonization. Likewise, Watson (2009) argues that the demonization of aborigines in Australia gave Whites a feeling of superiority over their colonial subjects, distributing little land in which they could reside. The demonization is directed toward people that are non-White and do not exhibit the same traditions of a Western civilization and who, therefore, must be civilized through systematic transfer of Western teaching that generally was not in favor of truly positively changing non-White subjects.

In the eyes of many, colonialism has done more harm than good because the word itself is highly contested in western societies. Lemkin (1994) describes colonialism as genocide, oppressing the native inhabitants in ways through exploitation and sexual abuse. The past acts of mistreatment against native inhabitants through genocide favored the colonizers who, in some cases, eventually outnumber the colonized in some countries, making it easier to create more rules and one-sided policies in favor of the European colonizers (McDonnell \& Moses, 2005). 


\section{Communication and Colonialism}

\section{Media}

Western Media in countries have continued to scrutinize other races, creating labels and categories that support the dominant, homogenous population. Wasserman (2006) asserts that "the bulk of scholarship devoted to the quest for universal media ethical values has come from the West" (p. 87). Western media and perceptions of race hence tie in with postcolonialism as, for example, women of non-White races are still objectified even more than White women. Identities have hence been shown to be problematic in westernized media, as media reproduces and shapes the racially bound idea of beauty noted earlier. Skin complexions that are not white have been deemed as undesirable in terms of beauty in advertising (Hall, 1996). In many western countries, women of color compare their beauty to mostly white models that can create a negative view of their own appearance (Frisby, 2017). For example, in colonial Burma, now Myanmar, articles and advertisements appealed to a white minority that had power over most the population. The advertisements promised non-White consumers that they could receive more racial and social benefits if they bought the cosmetics (Amato, 2009). As in many postcolonial countries, this sort of action from media organizations privileges one type of skin complexion as attractive and is still directed and linked to whiteness. Media in postcolonial countries often puts minority groups, like Blacks or Native Americans, in stereotypical roles of being either primitive or poor because of their identity. Imre (2014) notes that "the postsocialist opening of national borders and media to the flow of diverse images, ideas, and people has begun to burst the bubble of racial exceptionalism" (p. 131). However, Western media will likely continue to scrutinize and objectify people of other racial groups due to of the lack of cultural understanding. 
In Mexican culture, lighter skin is often strongly connected to wealth. Villarreal (2010), in describing racial issues in Mexico, asserts that many Mexicans have a strong desire for whiter skin complexions because of European colonialism. Villarreal admits that the racial issues exist not just in Mexico but in many Latin American countries. In Latin America, race has become prevalent due to social standings and political attainment (La Cadena, 2001). Positive media coverage for non-White subjects in postcolonial states is rare. Alhassan and Chakravartty (2011) assert that "the pedagogic relationship between the postcolonial state and Third World subjects meant that state censorship of minority or oppositional perspectives was also justified for the larger purpose of national development" (p. 372). Many subjects of "third-world" countries were silenced by people of higher positions because of control of the colonial government and the need for there to be regulations against colonial subject outcry. The reason for silence of nonWhites in colonial countries is likely due for the little care in value of life of non-Whites from people in higher positions of power.

Through a postcolonial lens, media play an advocate role in dealing with postcolonialism, often representing biased views of people of other ethnicities and displaying them as being poor and uneducated. Said (1978) agrees that technology and media are important for audiences to have a better understanding of racial identities. Media can also be used to promote and justify colonial views. Fernandez (1999) asserts that "many of the images created by these artists bring to the digital realm the subjects of colonialism, imperialism, and their legacy in the form of immigration and transculturation" (p. 13). Media in postcolonial times often demonize people of a certain race and religion to gain political support for chosen ideals, as previously mentioned. Fernandez argues that the media's role in postcolonial societies is underdeveloped due in part the fact that theorists are likely to be White and not have a basic understanding of all races and their 
political suffering. Some forms of Western media will likely continue to demonize certain races of people until a better understanding of race and culture can be properly established.

In most homogenous countries, it makes sense that little understanding of other nonWhite people would be an issue. Cere (2011) states that "media studies have always been concerned with issues of representation, stereotyping, identity formation and ideological workings of popular media cultures" (p. 3). Western media organizations usually identify problems in political television networks and internet groups favoring a one-sided view based on postcolonial thoughts against non-White inhabitants. The problem with media outlets in a postcolonial world is that non-White people continue to be underrepresented groups and face hypocritical scrutiny based on biased views. Cere goes onto mention that the racial silencing of non-White people is an ongoing issue that has reoccurred from colonial to postcolonial times but emerges mostly in the times of major crises or dramatic events. In a sense, western imperialism has gone about creating media that continues to objectify ethnic minorities, particularly in times of crises when it can become easier to blame other races of people in dramatic situations.

In postcolonial territories like Hong Kong, westernized media have managed to bring about the rise of feminism and protest, opposing communist policies from China in recent years. Chan and Lee (2011) describe that colonialism did bring more innovative ideas to colonial countries despite their being under the foreign influence of Great Britain. In many postcolonial countries, media have managed to help these countries better identify themselves with the rest of the world. However, in face-to-face communication in a postcolonial world, there continues to be a racial gap in that media often continues to portray as being biased and often asserting racist assumptions of groups that are considered ethnically or nationally different. 


\section{Interpersonal Communication between Races}

Interpersonal communication between people of different groups has become more common in westernized countries due to increased immigration from non-White countries in Asia, Africa, and Latin America. An example of this communication can be seen between patients and doctors. There could be large differences between a doctor and patient since the doctor could be White and the patient being non-White, possibly being poor and not as educated, leaving for issues for stereotyping in communication (Cooper et al., 2002). Discrimination between physicians and different racial patients has since been largely documented. Schulman et al. (1999) concluded that a patient's race could determine a physician's decision on which treatment best fits their patient. Communication between doctor and patient then may display racial issues regarding treatment. Mistreatment of patients of different racial groups may be because of postcolonial ties. Regarding interpersonal communication, Dixon (2006) describes that, while many Americans may not believe in a dominant race, most are aware of the existence of stereotypes of minorities.

Teaching and implementing systems of racial understanding would likely benefit all racial groups in eliminating the common assumptions and stereotypes the groups hold of one another. Singh and Rampersad (2010) emphasize that problems like racism can best be handled through learning institutions so that speakers can facilitate open discussion and have a better understanding of people from different racial and ethnic groups. Explaining racial issues to people of younger ages will likely decrease their negative stereotypes of different groups. One issue with researching group prejudice is that people are often not aware of their own racial thinking towards other racial groups (Iyengar \& Barisione, 2015). Reducing racism and prejudice in interpersonal communication between races has seen improvements over time. 
Communication Accommodation Theory (CAT) is useful in this study because it reveals how people of different cultures address one another and their changes in communication behavior through over- and underaccommodating. Often, postcolonial nations and their whiter residents will hold higher authority over non-White positions, creating unequal balances, leaving communicative adjustment often to the responsibility of those colonized. Many indigenous people living in countries continue to have little power, which allows privileged elites to exert their own biased rule. CAT will be useful in revealing the misunderstanding in communication between races of people. This will expose the reoccurring problem of people in certain nations imposing a colonial power-like structure upon all citizens. While the term "post-colonial" stands, imperialistic methods will still prevail, further disadvantaging poorer and often non-White people. The next section will discuss how people accommodate their communication, leading to the research questions. CAT may yield a better understanding of how people accommodate and accentuate their speech differently to people that are ethnically different.

\section{Communication Accommodation Theory}

CAT has been a primary theory for explaining how we change our speaking in communicating with others. Giles, Coupland, and Coupland (1991) summarize accommodation as "a multiply organized and usually complex set of alternatives, available to communicators in face-to-face talk" (p. 2). Accommodation plays a large role in countries like the United States in explaining how many people of different races and ethnicities may accommodate their communication to people in the different dominant groups. While this sort of communication is not seen as bad, the communication itself is seen as a normative when there are changes in speaking behaviors between different ethnic groups because of their identity. People usually adjust their communication toward someone that they may perceive as ethnically different. 
Gasiorek and Vincze (2016) state that "CAT posits that speakers generally converge in their language use if they want to affiliate or decrease social distance with their interlocutor (i.e., emphasize solidarity, convey liking) or want to facilitate comprehension" (p. 306). Humans naturally change the way they speak around the world because of the new environment they are in or the type of people with whom they surround themselves so that they, possibly as outside speakers, can blend in with the rest of their host society. CAT essentially explains how and why speakers make changes based on another speaker's behavior or perceived group belonging and how those changes in speaking are perceived (Gasiorek \& Giles, 2012). When accommodating to ones' communication, speakers adjust their speaking behavior based on how they see someone else.

\section{Convergence and Divergence}

CAT suggests two major moves that speakers can make when adjusting their behavior. Converging is when individual speakers adapt toward each other's communicative behaviors. Linnemann and Jucks (2016) explain, "One important function of convergence is that it facilitates comprehension" (p. 687). Many people who converge to a native speaker do so to identify with a group to gain something of importance. Many other factors can lead to converging, such as a desire to better identify with another group of speakers and share a similar identity. In sense, acts of converging can be positively motivated. Pitts and Harwood (2015) note that in productive communication, more speakers are willing to converge. There are, overall, multiple reasons as to why people converge, even simply out of the person's immediate or permanent desire to control another speaker.

Divergence can best be defined as speakers moving away from the communication style of the other speaker through a desire to be separate from the other communicator (Gasiorek \& 
Giles, 2012). Speakers that diverge may wish to disengage from another speaker for several reasons such as simply wishing to speak and treat everyone similarly. Diverging can also be sought by those who choose not to engage in speaking with others either because they wish to distinguish themselves from the other person or group or they simply have an unwillingness to speak in the manner of the other speaker. Diverging can be non-accommodative; therefore, diverging from others could be considered rude because the speaker is simply not willing to engage in speaking to someone else. Gasiorek and Vincze (2016) explain that speakers often diverge to lessen their communication. Many times, during a conversation, speakers may choose to diverge because of dissatisfaction with the other speaker.

Gasiorek and Giles (2012) mention how speakers evaluate and make attributions based on the encounter with the other speaker and the behavior. Converging in conversations can likely increase positivity between two speakers, establishing better relations. Pitts and Harwood (2015) explain that converging can lead to positive outcomes and lead speakers to a better understanding of group identity. Many speakers may also converge due to similar values (Gasiorek \& Giles, 2013). A person not accommodating his or her speaking could possibly result in bad relations with the other speaker. Convergence will likely improve a conversation or complicate conversations more depending on if a speaker is over- or underaccommodating.

It is also possible to converge, but to do so ineffectively. Overaccommodation can lead speakers to feel patronized if other speakers are doing more than necessary to adjust their behavior. Overaccommodation occurs when a speaker changes their communication too much towards the other person, whereas under-accommodation is not adjusting one's communicative behavior enough to speak effectively (Gasiorek \& Giles 2015). Accommodating one's communication toward a speaker can often be difficult because using the communication style of 
a different culture or group can be perceived as offensive. Rice and Giles, (2017) assert that it "is then necessary to construct a convergence between the intention and the meaning" (p. 131). In many conversations, overaccommodating can be accidental, but it still leaves issues in terms of properly accommodating another speaker.

When should we converge and diverge. As Giles et al. (1991), stated, we mostly converge when we want to adapt or accommodate to another group of speakers' communication. In intercultural situations, speaking with people that are ethnically and racially different can reveal how a Black male may accommodate and change their speaking to a White male differently than someone of his own racial group. A Chinese student, for example, at a westernized institution may converge to other western colleagues speaking to appeal more to their liking, but with other students of the same ethnicity, the Chinese student is likely to maintain his or her communication style — that is, keep it the same —or even diverge from the western style to appeal to members of their own ethnic group. These types of situations have occurred for centuries since people of different cultures began to meet. Minority speakers are likely to converge to the dominant speaker; however, if a member of a group is proficient in another language, the student might feel more inclined to converge to the other minority language if surrounded by friends of that culture (Bourhis, Sioufi, \& Sachdev, 2012).

In terms of biological sex, men and women have been seen to be more accommodating to someone of the same sex. Baker (1991) argues that women in the workplace are often not given as much power because of discrimination and thus not able to speak as much as men. These acts of discrimination and the ongoing interruptions of women by men still reveal the unbalanced treatment that men receive compared to women in accommodation in the workplace. 


\section{The Present Study}

Despite the fact that we live in postcolonial times, there has still been little research done on racial relations regarding accommodation in face-to-face communication. However, because media outlets, like television, and social media websites, like Facebook and YouTube, have had such strong impacts on the way we think about others and adjust our communication when speaking with them, it is likely that people do accommodate their communication toward others differently based on race and based upon postcolonial mindsets that have likely gone on for generations.

The literature reveals just how these ongoing changes in postcolonial times, with the help of media, have continued to alter the view of how people view and accommodate their communication toward others based on race and ethnicity. In communication research, postcolonialism has been applied primarily to media outlets and texts as biased systems and sites that greatly dictate how we should perceive someone of a different race and even sex. This, then, ties in with postcolonialism because it reveals that people may not have advanced in terms of acceptance of others but merely use more advanced tools in replicating the sort of systematic racism that is still used while still retaining postcolonial mindsets. Even people that others look up to or admire may have biased views of other ethnic or racial groups, as media channels these views, giving thousands or millions of other people these same mindsets, thus leading postcolonial views to prevail in the media even in a more progressive $21^{\text {st }}$ century. However, postcolonialism has rarely been used to address face-to-face communication.

This study examines the reason behind message accommodation based on race, sex, and identity. There continues to be a large force pushing for equality through means of more progressive media, but problems of racism and stereotyping remain because of biased media 
from television to websites. In other cases, these discriminatory attitudes are taught from other family members and have persisted through generations (Nast, 2000). Colonialism may play a large role in how we accommodate our communication toward others, based on messages received through media and interpersonal communication between ethnic groups. Through media, these sorts of stereotypes continue, from objectifying one's race to believing that one person is simply better than the other because of skin complexion and biological sex. Previous research has proven that these sorts of problems still occur. Currently, there are many places, not just in the United Sates but around the world, where there remain issues in face-to-face accommodation based on the simple notion of skin color. It is unclear why some speakers may accommodate their behavior toward others based on race, which then leads to the question of why we act the way we do based on the perception of a different speaker. This argument leads to the following research questions.

Studies have shown that, in racial groups, there is likely a stronger feeling of safety and security when people of the same group are together. From the literature above, evidence has shown that people are likely to identify someone that may be Black from White, signifying the different characteristics that they might display, thus creating false stereotypes and creating racial categorization. The current issue regarding self-identification leads to why people continue to create racial labels.

$\mathrm{RQ}_{1}$ : How do people self-identify within their society?

Additionally, it is important to observe whether media have some effects on the minds of how people identify other races. Based on evidence of people changing their social behaviors when communicating with people of different races, it is likely that people treat others differently in terms of communication. The literature review has shown that postcolonial media 
do have some influences on how people see one another racially, but do people see them playing a role in how they communicate in face-to-face interaction?

$\mathrm{RQ}_{2}$ : What role do participants feel media have in how they view people of different race/ethnicity and how?

Due to lack of data regarding why people change, there is also a need for further research as to why speakers accommodate others in different ways because of race. This question will likely open discussion as to why participants do or do not change their speaking when encountering people that are ethnically and racially different than themselves. When discussing postcolonial stereotypes, it is easy to draw conclusions that people are likely to treat others differently due to years of unbalanced wealth and political power. However, not enough research has been done to record how communication is affected when two people of different races communicate.

$\mathrm{RQ}_{3:}$ In what ways do people accommodate their communication to others based on race? $\mathrm{RQ}_{4}$ : Why do participants feel that their communication style changes when communicating with someone of a different group?

\section{Conclusion}

This chapter has examined many studies based on race, gender and media, including research regarding CAT and postcolonialism. It also presented a theoretical framework that forms the overall foundation of the study. This chapter has covered the gaps as to why people may choose to accommodate to others differently and proposed a series of questions that will address these issues. As many people, not just in westernized countries but around the world, become more progressive in their attitudes toward people different in race and gender, there remains an underlying series of questions about whether, why, and how people still change their 
speaking just because of someone's racial appearance. The next chapter will focus on the methods used to carry out a study to address these questions. 


\section{CHAPTER III: METHODS}

The last chapter focused on postcolonialism, the effects of colonialism, and communication accommodation as they relate to postcolonialism. The chapter presented postcolonial studies as the specific focus for understanding as to why people may accommodate their communication toward others differently. This chapter will now explain how the data were collected and the procedures that were followed in the current study.

\section{Participants}

Participants were comprised of university students from a midsized Midwestern university of at least 18 years of age. The student sample is appropriate because of their age and likely increased exposure to people of different ethnicities compared to someone who may be older and lives in a small, homogenous town. A total of 135 participants partook in the survey. Thirty-eight of the participants identified as East Asian while 41 participants indicated that they were White/Caucasian. There were 17 participants that identified as Black, 14 had marked as being Hispanic, six participants identified as Middle Eastern, seven marked as mixed race, one participant marked as Native American, three participants had checked their identification as other, one participant has marked as Pacific Islander and two participants marked South Asian. The remaining participants identified with the other races available on the survey, while only one participant asked not to be identified. Fifty-four participants identified as male; 75 participants had identified as female, with the remaining participants identified as other. Most of the participants' ages were around mid-twenties ranging from 20 to 25 where the mean age was 24 . Participants could only choose one identity.

I recruited the participants through self-selection, specifically through an email message invitation sent to a randomly selected set of students who had volunteered to receive invitations 
to studies, and through social networking sites like Facebook. Subjects were told that the study would be investigating how they communicate with people from different groups and how they might treat people from those groups. The recruitment message specified that the study was looking only for individuals that would identify as university students due to the nature of the goals of the study and who are at least 18 years of age.

\section{Data Collection}

Students who desired to participate logged onto an Internet website hosted on Select Survey, a survey software hosted by my institution that allowed for the encryption of data. Before the participants started the questionnaire, they were provided with the statement of informed consent, regarding the types of questions that were asked and the purpose of the study and why it was being proposed. The statement informed them that they could withdraw from the study at any point without any repercussions and that they were free to contact a counselor if they felt distressed at any moment. The questions were open-ended, with the participants typing answers of varying length for their responses. Participants received space equivalent to a two to three sentence response for each question but could type more.

After demographic questions concerning ethnic identity, sex, and age, the main questions regarded any recent times participants may have interacted and communicated with someone of a different race, with a total of 10 open-ended questions. This set of questions would be used to better understand how participants accommodate to the communication of others and whether their treatments differ between other races compared to their own. The survey appears in the Appendix. The first set of questions asked about how participants identified themselves in reference to other racial groups. Next, respondents answered questions regarding possible changes in their communication with people of different ethnic groups and the reasons for those 
changes. The participants finally answered questions regarding whether they felt that media influenced their thoughts and preconceptions of how to interpret others of a different race.

\section{Procedures}

All questions were written in English because all students were university students at a U.S. American university. Once consenting to the study, participants identified what race they belonged to and provided their age. There were a total of 10 racial/ethnic backgrounds to choose from as well as options for choosing "other" and "mixed race." Those who choose not to answer this question were directed to a message that commended them for participating. It took participants 20 to 30 minutes to complete the survey. All data gathered were anonymous because I did not have any access to personal identification information or IP tracking capabilities. If participants declined to participate, then they were commended for their time and the survey closed automatically.

Questionnaire. The questions regarded any recent times participants may have interacted and communicated with someone of a different race. This set of questions would be used to better understand how participants accommodate to the communication of others and whether their treatments differ between other races compared to their own. The survey appears in the Appendix. Specifically, questions regarded four areas of identity and communication. The first question asked would be the identification of other racial groups while also asking about being influenced by the media. The respondents answered the questions regarding their thoughts about their communication with people of different ethnic groups and if their behavior changed during their conversation. The participants also answered questions regarding if media influenced their thoughts and preconceptions of how to interpret others of a different race. Lastly, the participants 
discussed their previous conversation went with someone of a different race and if their communication with the speaker was altered in some way.

\section{Data Analysis}

The data from the survey questions being analyzed required quantitative and qualitative techniques because of the varied responses. Closed-ended answers required simple frequency counts, with a mean calculation for age of participants. To answer the research questions, thematic analysis of the open-ended questions was used. Data from the open-ended questions were developed into themes and analyzed qualitatively. I derived patterns of similarly occurring

in the data as regarding each research questions (inductive data analysis). Each separate idea was within an answer, as it related to research questions, constituted a unit of analysis; that is, if the answer did not address a question, it did not have any units, but if a single answer has more than one idea relevant to a research question, it may have multiple units.

The units then constituted information available for categorization to determine the outcome of the study and also related to the research questions. Specifically, I used Spradley's (1979) semantic dimensions (e.g., "x is a type of $y$, " "x is a place where y occurs") to locate ideas to address each question. I consulted with an expert scholar to find units that indicate the ways in which participants change their communication when speaking with others in RQ1, while the types of meanings they draw about race from the media regard to RQ2. For RQ3, categories concerned specific ways of adjusting one's communication. For RQ4, categories the internal or external factors participants perceived influenced their communication behaviors to change. Numbers were assigned to categories for the survey question related to RQ1. All borderline decisions were discussed with my advisor. 


\section{Conclusion}

This chapter has described the methods that were used in the present study, beginning with an explanation of the recruitment of participants and the procedure for running the study. The chapter also described the online survey procedure and outlined the questions that participants answered. Lastly, the chapter outlined how the data were analyzed. The next chapter presents the results of the study. 


\section{CHAPTER IV: RESULTS}

In the previous chapter, I discussed my methodology by relaying important information relating to the study. The 135 participants answered a total of 10 open-ended questions regarding race and accommodation. After I collected the data, I placed the participants' responses into representative themes. In this chapter, I will reveal the results pertaining to my four research questions. I will first discuss how people perceive their ways of communication towards people of different ethnic groups while using content analysis. The structure of this section was based from Jakobson and Halle (1956). In recognizing the answers in relation to the literature review, I framed the answers to relate how participants may enact certain actions with those they are speaking to from different ethnic speakers.

\section{Self-Identity}

Research question one pertained to how participants identified the ethnic group to which they belonged. To properly understand participants, it was important to have them state how they saw or determined their racial and or/ethnic identity. The answers would then provide context to their responses about communicating with people from other ethnic groups. The need to consider self-identification was to ensure that participants knew of their own identity while speaking with different groups. Recoding the participants' behavioral attitudes in the answer then may reveal some understanding as to why a participant treats someone different because of identify compared to someone who is not the same racial or ethnic group. The open-ended responses suggest five categories: culture, physical traits, national identity, and language.

\section{Culture}

There were 21 participants who also ethnically distinguished others by culture, explaining that cultural behaviors and customs were how they would differentiate themselves from others. 
One participant explained about asking other ethnic speakers their ethnic background to understand them:

I usually ask where they are from to know what kind of background they might have and traits that I might relate to. But if they are ethnically different from myself, I tend to talk about my own cultural background, language or mannerisms that are experienced by different people.

Having a large Asian population taking the survey impacted the findings because it showed participants viewing themselves coming from similar cultural families. Some participants brought up their ethnicity as being Chinese and being raised with similar cultural values. A participant who identified as Chinese noted that her cultural upbringing brought her to be more reserved towards people that she believed to be ethnically different:

I distinguish myself different than others because I am living up on my cultural value, specifically a Chinese value, and my behaviors are bounded by my cultural practice, norm, and expectation. For example, I am super family-oriented, and I think about the collective interest of my family of whatever I do. [I] as a foreign international student also carry cultural expectation of my own country of origin. so, when I meet people in the U.S., I always be aware of what I do or say, I would control and suppress my anger even if I am not agree with some of the social practice here. I would not talk about politics and express my true anger toward policy that harm the interest of my own country. These make me uniquely different than most of other ethnic groups or racial groups because I believe I am carry the cultural identity of my own groups.

Another participant who identified as mixed race had a unique response in identifying with a certain ethnic group explaining that, because he was mixed race, half White and Black, 
there were many ways that he identified with Black culture, but there were also certain instances he identified with non-Black cultures. The statement could also lead to future research into mixed race identities. This statement shows that the notions of race and culture were interconnected. Essentially, a participant could be of two cultures, and, while communicating with someone of one culture, the participant may be unaware of which culture to identify with thus showing how strong race and culture interconnect. Two participants that identified as White seemed to feel more comfortable when speaking to someone at least that shared a similar culture than someone who may have different cultures. An Indian participant for example expressed preference with speaking with someone that also shared the same culture in a foreign environment while sharing the same language and values. The examples from the participants then show that culture and race are important when communication is established between speakers from two different ethnic groups.

Physical traits. When participants were questioned how they ethnically distinguished themselves from different speakers, 27 participants stated skin color. A White participant said: "The easiest way to distinguish me from others is skin color; I am White, and I become especially aware of that when I am communicating with someone who is not White."

Participants explained that they often identified their differences in communication with an ethnically different speaker in terms of other physical traits. One participant explained that not only ethnicity, but ancestral traits passed down to ethnic speakers were noticeable:

I distinguish myself from other ethnicities by genetic material, the way we are made up and look. Genetics is the clearest way of seeing the differences since it doesn't only give you the looks, but also, I believe certain traits of character and tradition are passed down from your ancestors. 
National identity. Fifteen participants brought up national identity when distinguishing themselves from ethnically different speakers. One participant ethnically differentiated as Chinese but also said political differences generated complications:

I am ethnically Chinese, but I usually identify myself as someone from Hong Kong because of political differences. I am proud of ancient Chinese culture since it has many characters in the language and it teaches values of respect, honor, peace, tenacity, wisdom, and others.

Another participant also brought up nationalities as ethnically identifying other speakers while also stating that she was made up of different ethnicities. The fact that she sees herself representing multiple ethnicities while being from only one nation suggests that determining one's nationality in terms of ethnicity could be complicated.

Some participants explained that it was often easier to speak to someone of a similar ethnic group but were aware of their cultural differences when speaking with people of different backgrounds.

Uncertainty. Many participants were uncertain about which race to choose from in identifying themselves, with some saying that they were made up of multiple ethnicities, so answering the question became confusing. One participant was not sure of his ethnicity: "I do not ethnically distinguish myself from others in a purposeful manner because I am unsure of my ethnic background." Other participants were uncertain about how to interpret the question. A participant who was unsure of her ethnicity explained how the question was difficult to answer because of the multiple ethnicities that she was composed of: 
It's hard for me to identify my ethnicity. I am a White woman, who was born in America, a country that is extremely diverse. I know my countries of origin that my families immigrated from, but my family doesn't have strong ethnic ties.

The participant emphasized that, because she was made up of other ethnicities of multiple countries, it became difficult to identify as solely one ethnic group in the survey. Many other participants were likely made up of other ethnicities but, in the survey, identified with only one ethnic group.

Language. Native languages were another distinguishing trait that participants noted as distinguishing themselves from ethnically different speakers. A Latino participant, whose family came from the Dominican Republic, differentiated him/herself based on races in the country:

The most obvious [trait] would be skin color, but my family is from the Dominican Republic where many people range from Caucasian white to Haitian black skin. So, I tend to notice other factors like the way someone speaks or behaves around others. There are many distinguishing characteristics between different ethnicities and even between those who speak the same language.

The United States, like other countries with multiple demographics, gradually has appeared to shift to have a national identity that includes a multitude of other racial groups, creating a more ethnically diverse country in terms of ethnic identity. This would then translate to having more identities representing the United States than previously.

\section{Media}

For research question two, I explored participants' perceptions of the influence of the media. The findings suggested that most participants share a negative view of the media (movies, news outlets), asserting that the news industry treats people of color differently because of racial 
differences by creating cultural biases towards different ethnic groups. The biases created only preview negative actions of an ethnic group, creating a negative perception from most viewers who watch popular, well-known news channels. Media texts tend to pit majority versus minority groups in showing negative sides of different ethnic groups, often those other than White, while underrepresenting or misrepresenting people of other ethnic groups and their cultural values.

\section{Favoring Other Groups}

A homogenous group within a nation will likely be able to establish control over other groups if that group is in the majority or simply has more economic or social power than other groups. It should be no surprise that at least eight participants asserted that, in the United States, there were biased accusations in the news; they believe that most shows in the media favor Whites over other ethnic groups, thus giving viewers a limited view of how other minority groups act, creating a space for misconceptions and implausible assertions:

I think the U.S. media tends to portray White people as more advanced, intelligent, rich, and educational than any other race or ethnicity. No offense, [but] I don't see any Asian American playing the protagonist in any of the movies, and I don't see any Blacks [who] are playing protagonist as often as whites in the media as well. Specially during the political election, once I turn the TV on, it's literally all Whites. I want to hear voices from different racial or ethnics groups as well. Too bad I did not find it in the mainstream media, yet.

One participant who was cautious of news organizations in the media said that movies and the news channels likely ignore other ethnic groups and only describe the negative aspects of other groups in favor of White cultures. When discussing racial complexities, most participants 
agreed that the racial intolerance of the media led to current issues in interracial communication, such as stereotypes of other ethnic groups:

The media can make anyone believe anything about an ethnic group via Facebook videos, articles, etc. For example, many Americans [watching media] tend to believe that all Muslim people are bad in some way just because of the way terrorists can make them seem as a people.

Another participant believed that the continuation of favoring one ethnic group over another can lead to negative consequences for younger generations: "You find the media tries to show that a certain ethnicity is only made of gangs, criminals, it [minority group] can do sports only but [is] not good for schooling, and this ends up affecting this [their] ethnicity."

A third participant criticized news outlets showing only negative sides of minority organizations, saying that ethnic groups like Blacks are mostly affected by media representations:

They'll show stories and images about a specific ethnicity based on how the media is telling the story. You decide from there on what you want to do with that information. For example, the riots and the shooting all tied to the Black Lives Matter and Blue Lives Matter movements. Some media show the awful side to Blacks by showing shooting at cops, destroying towns, rioting. Then on the other hand you've got the media who shows that, but shows the why to it all. They [media] hurt and distress Blacks.

\section{Stereotypes of Ethnic Groups}

Fifty-four participants had an overall negative view of the media, where they believed that news outlets follow their own agenda, seeking to divide ethnic groups to gain more favorability than other news stations. One participant who thought that stereotyping was 
common for news outlets believed that news shows have a strong, direct influence on their viewers:

Sometimes I think the media perpetuates negative stereotypes associated with different ethnicities (e.g., Asians are all good at math). These stereotypes are then reinforced into Americans' image of people ethnically differing from themselves, which leads to prejudices.

Most of the participants' views of the media were similar in terms of the reproduction of stereotypes in television, as mentioned by the previous participant, demonstrating participants' overall negative views. Some participants believed that news stations reported too much negative news regarding certain ethnic groups:

I feel that the much of the news media is hurting the relations between different ethnicities by cultivating an "us versus them" mentality within the viewers' minds. This then creates a toxic and unsafe environment for those who may be different.

This participant's response suggests that generalizations from news channels have only created more negative views, explaining why most of the participants stressed their discontent with Western news outlets.

Another participant who was more negative about the media said that news outlets continue to place minority groups like Blacks as criminals:

One group of people might be stereotyped as being criminals on the news, and all the stories covered show that group of people in a negative light. For example, African Americans tend to be covered in a negative light on Chicago news channels. They are also still stereotyped on TV and in film. While some media tries to move away from negative stereotypes, they still exist and are still perpetuated in media. 
Many participants relied on their own history of racial understanding in their argument against the media, stating that in the United States, people of color are often stereotyped in that certain ethnic groups are perceived as troublesome due to negative coverage from news outlets. Another participant believed that common stereotypes are strongly connected with negative perceptions on the part of viewers: "I think the media tends to fit people into certain molds based on how [the] majority white culture has viewed them. A lot of base [biased] assumptions and stereotypes people have been shaped by the media."

In almost all cases, participants believed that news outlets in the media had caused issues for groups of ethnic minorities. News outlets demonizing other minority groups by showing negative actions and relying on biased assertions were two accusations described by the participants in the issues made by popular news channels. The data suggest that participants feel that news outlets do, in fact, separate different ethnic groups because of their bias and division of other ethnic people. One participant believed that these outlets should discontinue sensationalizing other ethnic groups:

I feel the media sensationalizes most ethnic stereotypes and differences. Big headlines in Facebook posts, newspapers, and the left/right news stations tend more to exaggerate ethnic differences between groups. I realize that people are different then me, but those differences should be celebrated and not seen as negative.

Positive views. Most participants had an overall negative view of the media, compared to only four who had positive views. A female participant viewed the media positively, saying that the media assisted in helping viewers learn about different groups of people. The participant asserted, "I think the media shows a fact that many people think that we are ethnically different. For me, it's a good way to learn about others, so I feel it's ok about the media." 


\section{Different Ways of Communicating Based on Race}

The purpose of the third research question was to understand how people perceive ethnically different speakers' communication and accommodate their communication behavior based on racial identity. 65 participants described how they changed their communication behavior where 25 said they did not change at all.

\section{Slight Changes of Communication}

Thirty-two participants said that they often would not change their communication based on someone's racial identity and, instead, would likely change their communication based on cultural backgrounds. One participant who stated he would try to be clearer, noted: "I communicate the same way with everyone. When speaking with someone that speaks a different language than mine, I try to speak clearer and with more pauses so that they can understand what I am saying." At least one participant revealed that he would speak slower when speaking with someone of a different race.

Participants came from very diverse areas; some participants who took the survey were international students and explained that they often felt that native speakers may have changed their communication. Many participants mentioned that changing communication was often not needed, stating that they would not usually change their way of speaking because they spoke the way they would to most people, regardless of identity.

Despite many assertions from some of the previous literature (Gasiorek \& Vincze, 2016)

that people may behave differently, several participants mentioned that their communication with ethnically different speakers was like that with any other speaker, regardless of race or ethnicity. In responding to one survey question about how the participant would communicate when interacting with people of different ethnic groups, one participant said: 
Just as I would anyone else. I'm an introvert at heart, so it's not easy for me to just start a conversation, but when I do I start by finding common ground. Whether it be a show, sports team, maybe I like their shoes etc... Often you find that if you have one similarity with a person, you'll have many others no matter if you're ethnically different or not. Another participant also explained that ethnicity was not of importance, saying everyone was treated the same:

I often communicate the same way to everyone. Ethnic differences often do not influence the ways in which I communicate. If an individual has trouble understanding my language, I may speak slower or accommodate to their need. It is important to note that a language barrier is independent of a person's ethnicity.

The previous example shows that a small group of participants perceived that their communication had remained the same without any need for changes. Slower communication was seen to become apparent in the answers despite participants' claim of equal treatment of others.

\section{No Changes}

One participant explained that he did not change his communication to appear fairer in equal treatment of everyone saying: "I try to speak to people of all ethnicities equally." A few participants stated that they would not change their communication but did not provide any valid reasons on why they would change.

One participant described trying to be polite, explaining there she or he made no changes being made to communication saying: "I don't think my method of communication differs based on someone's ethnicity. I suppose I try to be as respectful as I can be in my conversation.” A 
third participant who claimed not changing, explained she did not want to change her speaking patterns as a reason for why she did not change her communication.

\section{Changes but not Specifying}

Some participants brought up changes in their communication, but were not clear on exactly how they changed. One participant who felt less comfortable with White speakers said he spoke better with non-White speakers:

I speak more comfortably and casually with ethnic minorities (non-White) because a lot of ethnic minorities share the same cultural values and struggles, so I feel more accepted and comfortable with them. With Caucasian people, I speak less comfortably/naturally due to cultural differences.

Another participant also added that he hardly changed his communication, but did so only to not appear racist:

Just normally between different races, we are all human. I do remember at one point though feeling like to needed to speak carefully with African Americans I didn't know. I don't know how or when I gained it or when it changed but I was worried I'd say something that could sound racist.

A third participant who admitted being less comfortable when speaking with non-White speakers also specified in changes, but stated feeling less relaxed around ethnically different speakers:

I tend to be less relaxed and open when I am talking to a different ethnicity. I assume the people of other ethnicity wouldn't understand my jokes, conversation content so well. Therefore, I tend to share less experience with them and speak less unless others are a very good friend with me. 
Another participant who talked about his languages varying between speakers also did not specify for her reason to change, but mentioned that her language may change: "Depends on the ethnicity. My language might change to try to match that of the person I am speaking with, trying to find common ground in similar words and phrases."

Code switching was also mentioned by another participant, but also with details unspecified. The participant explained: "There are certain figures of speech that may be avoided or eliminated, while the inclusion of other terms or figures of speech may be added. Code switching is a reality for me, most definitely."

Another participant, who identified as a lesbian, mentioned her speaking patterns would change but did not go further in depth:

I am a candid and outspoken individual, so my way of speaking does not change. Interestingly, I also identify as a lesbian. I've noticed that more empathy is provided by non-queer white individuals towards the LGBTQAI community; however, these same individuals do not show any interest showing empathy towards issues concerning ethnic differences. Someone should investigate this further.

A mixed-race participant said that adapting to someone else's communication was also useful: "Being mixed race, I find myself trying to adapt my communication style to the other person."

\section{Changes in Verbal Communication}

Paralinguistic level. One area of change that appeared from some of the answers regarding communication were changes in aspects that are vocal but do not include verbal content, things such as pronunciation, rate, and tone. 
Phonology. There were at least several participants who included that their communication was different but being more something vocal than verbal. One aspect of change is phonology, which deals with the pronunciation of words. Several participants noted that their communication did not change, but their accents did change in addressing other ethnic speakers. One participant who stated her accent changed but said that there was little change in her communication, but her accent when speaking with someone of a different group, in fact, did change. The participant went on to say: "I do not consciously change anything while communicating with people who are different from me, but I guess my accent differentiates me."

There were 23 participants who mentioned that their communication changed based on different motivations and earlier preconceptions of the type of speaker they may encounter. The motives for communication will receive attention in discussion of RQ3, but here, they relate to different aspects of vocalic change. Twelve participants emphasized that they would try to be more respectful when speaking with ethnically different speakers. In one case, in trying to appear more respectful, one participant explained trying to speak slower for the other speaker to create a better understanding where participants noted that mannerisms become more noticeable. One participant who stated that he would be more nervous when speaking with others asserted: "I tend to become a bit more nervous and become frustrated with myself that my mannerisms become more forced and language becomes a little awkward" (emphasis added). Being more forced may relate to pronunciation or rate (vocalics), and awkward language might refer to word choice, which will be discussed below. One participant who had identified as Indian said that she felt more relaxed when communicating with friends of the same culture and race:

If I am talking to my Indian friends, I will feel more closely related since our cultural distance is closer than that of Americans. I can express myself a little more freely and 
openly because I know that we share a similar cultural value and view about certain issues. If I am talking to an American, I might adjust and withhold some of my personal thoughts about the issues, because I don't want to be judged, or be criticized. Again, being more "relaxed" and "free" in conversation may relate to vocalic pronunciation, though her perceptions also impact the content of her words.

Some participants noted reasons for their adjustments in vocal characteristics. One participant described how she handled a conversation with an ethnically different speaker saying that when she would talk with international students she would try to speak in a more relational tone and listen more carefully because of language barriers that might hinder a conversation. Another participant suggested slowing communication but to appear more considerate for someone who may not speak English well enough saying: "I communicate the same as I would of someone who was ethnically similar. If they had a more basic understanding of English, I might speak to them slower or take more consideration to make sure they understand me."

Throughout the surveys, there were no traces of speakers feeling that they had angered an ethnically different speaker based on the repetition of their communication. One participant did say that if the speaker is from the same ethnic background, then her communication would likely change such that better communication could be established without generalizing the ethnic speaker prior to communication. The underlining assumption made was that a speaker who appears ethnically different could also speak just as naturally, thus leading to fewer changes in communication.

Another interesting point was made by one participant who said that her way of speaking changed after living in the United States. The participant explained: "When speaking with Americans, I unconsciously adopt an American accent. But in interacting with people from 
similar cultural background as me or ESL speakers, I adopt my natural accent while speaking with a hint of an American accent."

Rate of speech. One participant who was noted using simple terms when speaking with different ethnic speakers revealed that the participant's rate of speech changed when speaking with ethnically different speakers: "Speaking with other ethnicities, I will slow down my rate of speech and use simple terms to not offend the other person." The participant explains that changing his speech rate would likely create more peaceful conversations that would not agitate the other speaker.

Tone of voice. At least two participants noted that their tone of voice changed when speaking with differently ethnic speakers:

My accent and voice tone will automatically change based on my own perception of the culture of such language. Since then, my behavior slightly changes as well because that will help me blend in the culture easily. For example, I tend to speak louder and more heavily in English than in Japanese. However, the habit of listening first does not change. Participants likely changed their tone because of the environment that they were in, compared to being in other settings with ethnically different speakers. These changes could also relate to intergenerational speaking (Giles et al., 1999). Speaking to multiple ethnic speakers could have also influenced the change of tone. Another participant who admitted to changes in his communication also mentioned pitch change, saying that his voice would often become lower.

Semantic level. Participants noted avoiding slang or using a simpler vocabulary when communicating with ethnic others and the use and non-usage of slang. One participant, who identified as African American, said that he spoke and used types of slang when speaking with 
Blacks, but would change his communication when speaking with people from other ethnic groups to appear clearer when communicating:

By nature, I use a lot of slang or street terms in my every day conversations. If I believe that will hinder the conversation in any way, then I will try to refrain from using slang. For example, terms such as hella, live, lit, sent just to name a few. In a conversation with my everyday friends, I may say something like, "Man, I was supposed to see so and so but they sent me." Within my group of friends and many others here in the States, they'd acknowledge that the person backed out of the plans without ever telling just not showing up or not responding. However, someone not familiar with that slang term may view that sentence as incomplete, expecting me to finish it with something that they may have physically sent me in the mail. Continuing, terms such as lit and live are terms I would use to describe a party or a sporting event or any gathering that is an above average/extraordinary time. This however confuses some of the older generations of my ethnicity, let alone different ethnicities. So, I generally just try to take the slang out of my speech.

Another participant mentioned learning slang and wanting to use it with other people of the same ethnic group, but did not, stating:

Most of the slang I use is drawn from American Rap artists, and I used to live next to a large group of students from Jaipur, India. None of them listened to much rap so I didn’t use the slang I had drawn from rap songs and learned from rap artists.

Another participant who identified as African American said that when speaking with other African Americans, the participant would speak using African American slang to enhance communication, which then signifies how people of the same ethnic group may use similar styles 
of word choice to better facilitate a conversation. The participant would often let the different ethnicity speaker begin the conversation:

Depending on a certain ethnicity, I always give them a chance to start the discussion and I try to talk like them. For instance, when I am talking with an African-American, I try to use their slangs, and accents so that we can hear each other.

Another participant who mentioned he attended a mainly Hispanic high school explained that he would change communication because of the abundance of students that formed a majority of the school's enrollment. The participant explained: "Because I went to a mainly Hispanic high school, when I am around friends or others from a similar background, I change my vernacular. I tend to do this with closer friends."

A second way that people changed their word choice was through the use of simpler words, depending on the perceived group of the other person. One participant explained changing their wording with one participant explaining differences in misunderstandings: My way of speaking does not change until I see if there is cultural misunderstanding. Then I try to change the words that I use for better understanding. Different ethnicities could be that people are from the same county or other countries. If the different ethnicities are from the same country then there shouldn't be much miscommunication, only the looks that's it.

Another was careful when speaking with differently ethnic speakers, saying that he was more aware of their conversation " $[\mathrm{I}$ am $]$ more alert and careful in the way I communicate including selection of words I use." The situation then demonstrated how some speakers may become more changed in terms of word selection during communication. 
Finally, one participant included both subthemes of slang and simpler language. He stated that his communication would change when communicating when encountering people of different nationalities:

I may speak slightly differently when dealing with people of different ethnicities, but only if they are new immigrants and English is not their first language. I would not use slang words and would speak clearly and describe things more.

Syntactic level. Only one participant expressed changes in his grammar in terms of sentence complexity changes when communicating with ethnically different speakers. The participant explained that, based on how much the participant knows the language, the participant will adjust communication: "It changes from simple sentences/questions to complex ones based on the other person's English knowledge."

Pragmatic level. Some participants stated that they would try to sound more proper in their communication with others. One participant who identified as Hispanic changed communication depending on certain races, saying:

It changes depending on who I am talking to. Sometimes I talk very proper with people who are white, or Asian. I tend to talk relaxed with more slang with black people. I tend to add more jokes with Latino people.

The participants' answers revealed that some speakers changed their communication, most importantly, in speaking more proper between Whites and Asians compared to people that are Black or Hispanic. Preferences in changing communication between races then could become more relevant through different participants. 
One participant who identified as Asian noted being more direct with certain ethnic groups compared to others when communicating. The participant mentioned expressing herself differently depending on the speaker:

I tend to use different ways to express myself according to which ethnicity I am speaking

to. For example, I talk more direct and easy with Chinese. More accurate and euphemistic with Americans, and sincerer with Indians, politer with Japanese and Koreans, etc.

In terms of interethnic communication, one participant related that less humor would be used compared to other ethnically different speakers: "I think specifically humor can be very different from culture to another culture. so, what might be very normal for my own culture, it might not be ok for another one. or might be meaningless."

\section{Changes in Nonverbal Communication}

Body language, such as nonverbal movements, also appeared in answers made by several participants who said that their gestures would change when communicating. One participant who made physical changes when communicating mentioned different changes in nonverbal gestures like head shaking, saying: "My nonverbal cues change. There are some ethnicities who shake their heads a lot while talking and every time I am communicating with them I do a lot of head shaking as well."

Another participant changed the speed of his communication; the participant described how the other speaker looks would impact how she or he would alter communication:

"Depending on the person's ethnicity, I will either speak in a slow, yet respectful pace, or I will speak at a normal speed, using body language to help simplify the conversation." 


\section{Conversational Patterns}

Many participants explained changing the wording of how they would address another ethnically different speaker. Another participant noted that in conversations with ethnically different speakers, the participant would try to be more attentive and listen when speaking with different ethnic speakers.

Topic choice and turn-taking. When speaking with another ethnically different speaker, one participant noted that the participant would try to find a topic that would best fit the conversation. The participant explained her reasoning stating that she did not want to offend others:

I will select the appropriate topic that doesn't offend them. However, try to be the listener rather than the speaker because you will never know when you offend them. I will only speak more when I know them better and we become closer like buddies.

\section{Reasons for Change}

The goal of research question four was to reveal, when there were changes in communication, what the reasons were for that change. Many participants explained they changed their communication for various reasons such as to appear more understanding. This section will provide an understanding of the reason behind the changes of communication pattern.

A reason for changing could be due to unnoticed mimicry, as one participant was also unspecified in describing his communication: "I find that my speech tends to imitate or mimic some of the characteristics of the other's speech." 


\section{Communication Clarity}

Gasiorek and Giles (2015) determined that people change their communication by either overaccommodation, in which speakers may be doing too much to accommodate a speaker's communication, or underaccommodation, where a speaker is simply not doing enough. Giles et al. (2003) note a major factor for desiring to converge could be to be more clearly "interpreted" or understood.

When asked about their most recent conversation with another speaker, another participant who worked with international students mentioned:

Many times, people from different ethnicities bring with them different speaking styles and registers. I tend to speak slower whenever I can unless if I am angry. Working with international students with various levels of English, I heavily rely on body language to get my points across.

A participant who changed communication to appear nicer, mentioned that they spoke differently because ethnically different speakers did not at first understand what he was saying. Another participant explained that communication was changed because of the language barrier that likely had persisted between the participant and the other speaker.

A few participants added that they would change their communication with an ethnically different speaker to appear more fun and enjoyable in the conversation, with one participant who changed communication to be clearer, saying: "Sometimes it is for the sake of perceived clarity. Often it is unintentional and done in an honest way to express enthusiasm in a conversation." 


\section{Impression Management}

Many participants stated they would try to shape their communication based on the other speakers' appearance. One participant said communication would stay the same, stressing that the participant did not want to sound racist:

Just normally between different races, we are all human. I do remember at one point though feeling like I needed to speak carefully with African Americans I didn't know. I don't know how or when I gained it or when it changed but I was worried I'd say something that could sound racist.

Another participant explained he also did not want to be judgmental for changing his communication towards others. By not being judgmental would likely explain how the participant felt around others and how he spoke. Although the participants did not specify becoming judgmental or trying to appeal to a group as related to image management, it became apparent that the participants did in fact want to secure their image in the face of other speakers. In accordance to not changing at least two participants said they did not change their communication, so they would not come off as being judgmental with one Hispanic participant explaining: "Because I didn't want to be judge off my appearance and communication alone." The other participant admitted communication was changed because the participant did not want to appear judgmental saying, there was a fear of coming off as a judgmental person if the participant's communication did not fit someone else's view.

When discussing not trying to change communication based on another speaker, one participant noted that comments about an ethnically different speaker may differ, not out of being racist but also out of appearing politer towards someone of a different race. In accordance to impression management, one participant mentioned changing communication to appear more 
serious to others saying: "There is a certain level of seriousness people will take with you when they hear you speak a certain way." Most participants discussed that they would change their communication due to the appearance of an ethnically different speaker to sound and look more proper. Another participant mentioned that changing their communication to be more "accepted" would be the reason for their change. An interesting point one participant spoke about changing his communication was to appear more professional when speaking with ethnically different speakers and expressing hope in being accepted.

An interesting answer came from a participant who had identified as a minority stating that changes would be made to how the participant spoke to not be stereotyped in in the media: I'm probably not confident enough to believe that being myself will put me in a perspective that I'm a negative stereotype. I want to avoid any preconceived notion they have in their heads of what I should be like based on their encounters with my ethnicity on the media.

Other participants could have had the same answer in terms of changing their communication to not be stereotyped. Another participant who changed communication to appear more considerate, wanted to increase comfortability with the ethnically different speaker: Sometimes I want them to feel more comfortable, other times, I want people think that I am a competitive and articulate person. I also want to be more considerate for speakers of other languages as I went through those process [sic]myself as well. Being cautious was also another reason as to why one participant had mentioned she changed her communication. 
Another participant added an ethnically different speaker might not find the participant interesting: "I think the other person may not think I am interesting assuming we have a different cultural background. The culture I am interested in may not be an interest to him/her."

One reason for not changing, according to one participant, was to not reflect bias: "I don't change my way of speaking. I refuse to let people feel comfortable spewing their uninformed biases." The participant stated he felt that changing his behavior could reflect bias about other groups or possibly reflect political correctness that the other communicator could reject. Another participant explained that they did not change their communication "because I didn't want to be judged off my appearance and communication alone." The reason as to why could be because the participant simply did not want to come off as judgmental.

\section{Conversation Quality}

Many participants mentioned changing how they communicated out of respect and comfort for the other speaker. A participant who believed assimilation was important noted that being respectful to another individual was necessary to establish positive communication:

Assimilation into culture, while respecting the culture and avoiding negative appropriation, is important to me as an individual. Language is an inherent part of culture, and shapes cultures and even neurobiology.

Comfort and enjoyment. One participant explained they did not want to worry the ethnically different speaker and wanted to show respect. Another participant who believed that changing communication related to establishing equality, said that expressing they would treat anyone with the same communication and respect saying: "I think it shows that the communicator cares about the discussion they are having and want to be equal with the other individual.” Most speakers who identified as being non-White noted changing their 
communication when approaching speakers from other ethnic groups to ensure that their style of communication was not difficult to understand. One participant mentioned his change in communication because of the mistakes he noted in the other speaker's communication:

I changed the way I spoke because I tend to pick up on mistakes and things that people would say and do. When I hung around the international students, they spoke English in a way that I was beginning to accommodate towards their speech patterns. But also, what I said in terms of understanding each other. I found that many of them are very open towards changing how they are, why can't I?

Many participants included changing their communication out of respect for the other speaker. One participant who expressed the need for comfortability when communication said he wanted to have the ethnically different speaker feel more comfortable when conversing, so he had changed the way he spoke. An African American participant desired more simple communication and expressed changing communication for acceptance saying: "It seems like it helps them more fully connect with me while making it easier to understand them."

Showing respect by properly assimilating to someone else was one participant's reason for changing communication to ensure there was no disrespect to the individual speaker saying: "Assimilation into culture, while respecting the culture and avoiding negative appropriation, is important to me as an individual. Language is an inherent part of culture, and shapes cultures and even neurobiology."

Another participant, who expressed the need for more comfort when speaking with others explained change in communication to make the conversation more enjoyable for the other ethnically different speaker. Reasons for why people that change their communication to make the other speaker have more fun have not yet been fully researched. 
A third participant noted that the change of communication was often unintentional and was meant to bring more enjoyment to the conversation, saying: "Sometimes it is for the sake of perceived clarity. Often it is unintentional and done in an honest way to express enthusiasm in a conversation.” Changing communication to appear more simple and enjoyable was another reason for speaking differently to an ethnically different speaker.

At least seven speakers mentioned that their communication was slower when speaking with ethnically different speakers, citing that trying to appear politer was a reason for a change in speaking:

Sometimes, I communicate in an extra careful manner since someone who is ethnically different may have taboos or such. I also want to show that I respect their culture rather than being judgmental (since racism is quite common in Chicago).

\section{Building Connections with the Other Speaker}

Most participants wanted to establish equality with the ethnically different speaker and explained this as their reasoning behind their change in communication. One Hispanic participant stated his reason for change in communication was to get his point across:

I was enjoying our conversation and wanted to learn more about his experiences in life. There were concepts I could relate to, but felt it was important to change my syntax so that it was easier to get across that we were both on the same page. Another participant also mentioned that he changed his communication for the other ethnic speaker to feel accepted.

\section{Conclusion}

Slowing communication was shown to be a primary type of change when participants spoke with others, which was a way of better accommodating other speakers. Even if participants 
did not try slowing down their communication, some noted trying to hide their nonverbal mannerisms. As for the media, negative views from participants showed that they felt that many news outlets in the media in the United States objectify and stereotype other minority groups. The consequences of this relate to viewers having prejudiced views of other groups due to negative coverage by news outlets. Participants reflected their distrust for the media along with stating that media organizations place all racial groups in categories, which could be due to postcolonial residue. Participants reported mostly positive relations with other speakers and stated that they were aware of their own ethnic identity when differentiating from others. The results highlighted cultural issues that remain in interethnic communication along with the realization of biased news stations that continue to create social divides among ethnic groups.

Although some participants reported not changing their communication, others noted that they do see themselves changing their communication when speaking with ethnically different speakers such as speaking at a slower rate to ensure proper understanding. The participants explained that changes in their communication served simply to better understand and respect the speaker in the conversation and not because of any racially held views. Most participants revealed their reason for changing communication was to simplify the conversation between them and the different ethnic speaker. The largest influence on preconceptions of other ethnic speakers, according to most participants, was racially biased media. The results of the study show many implications for future research, which will be discussed in the final chapter. 


\section{CHAPTER V: DISCUSSION}

The purpose of this study was to examine the communication between speakers of different ethnicities to see if that communication can be explained through open-ended surveys using thematic analysis, while providing more content on a topic that has not been as thoroughly researched. Observations of possible postcolonial behavior was conducted, but the data only revealed that major news outlets in the media were shown to show such postcolonial resemblance as described by the participants. A major reason for change based on the results was for group acceptance. Participants noted wanting to establish comfort for making changes in their communication while no speaker mentioned changing based on negative racial aspects of the other speaker.

As my research was primarily on changes in speaking behaviors, it made sense to conduct surveys from college-aged participants in hopes of obtaining responses from a group of people who have likely mingled more with those from other ethnicities compared to other generations in the Midwest. One hundred thirty-five people who had a recent conversation with speakers from different ethnicities and were willing to describe changes, if any, in their communication participated in the study. I chose to focus on changes in speaking behaviors between people of different ethnic groups because of the increase in diversity, particularly within Western countries, where the changes in speaking behaviors will likely occur because of major demographic changes. Along with changes in speaking behaviors, I felt that postcolonial influences were likely to occur while individuals were dealing with communication with people from different ethnic groups.

The previous chapter presented qualitative results that I used in the study. Using qualitative research, I obtained a better understanding as to why people may change their 
communication because of another speaker's ethnicity; however, I found that reported changes in speaking behaviors were not as closely related to postcolonialism as previously thought. In this chapter, I will discuss in more detail the experiences from the participants' communication with other speakers in response to the research questions. I will then discuss the strengths and limitations of the study and finally will go over opportunities for future research.

\section{Summary of Findings}

The study focused on participants' changes of communication with speakers of different ethnicities and how they might adjust their communication with these speakers during their conversation. The first step was to conduct thematic analysis of the responses to the open-ended questionnaire. A thematic analysis created better opportunities to locate certain units of data and compare certain issues of communication from the participants' perspective. Overall, the results from the study showed that speakers sometimes make minor changes when speaking with people of different ethnic backgrounds, and such changes might be based on their perceptions of their own identity and media representation.

The overall purpose of research question one was to see how participants would identify themselves compared to other ethnic speakers. The results from the question showed that people will likely identify their own ethnicity with people of their own skin color. Other ways of seeing one's ethnicity include culture, language and nationality. The results reveal that some participants do in fact have preference for speaking to others of the same racial group. Besides, racial preferences, another reason for hesitancy towards communication with other groups was nervousness. The research then echoes Dixon (2006), in that people are aware of ethnic differences. The results connect with the first question based on how participants were aware of their own identity and speaking with someone of a different race. The relevance in results 
relating to postcolonialism would be that speakers may behave differently when communicating with other ethnic speakers but not in a negative way. Media from the results section revealed about the second question was that major news outlets could in fact create racial categories, which then can lead to the residue of colonial mindsets present in the minds of people that racially discriminate in the media. The results proved that from the last two questions regarding changing communication, that participants did change. Participants were shown to reveal signs of change but in the form of understanding and not of forms of postcolonial discrimination.

The responses from most participants, in accordance with question two regarding the role of media, revealed strong emotions towards the media, stating that news outlets represented biased views towards certain ethnic groups. The results revealed that most speakers admit that branches of the media such as news outlets reflect racial biases towards different ethnic groups while only showing negative sides of these groups. For example, news outlets in the media provide negative coverage of African Americans and other minority group and exclude crimes of the Whiter majority. Many participants agreed that the sort of messages created by the media would not only generate negative views but also show only the negative sides of other racial groups which, as mentioned before, leads to biased preconceptions. Regarding the third research question covering what ways, if any, participants changed their communication based on race or ethnicity of the other participant. Participants described their communication to become slower, with some participants becoming more careful in choice of wording while trying to be more understanding of the speaker that was ethnically different from them. Participants continued to discuss certain instances while they changed their verbal or nonverbal communication based on how they saw someone as ethnically different. Perceived differences in language, culture, nationality, and skin color or other physical characteristics of the other were deciding factors in 
whether participants changed their speaking behavior. Altering communication based on different speakers was not seen as being negative; rather, participants saw it as being more understanding of speakers of a different ethnicity. Those participants who did change their communication stated that changing their communication would not only progress the conversation but hopefully increase the quality of communication for both speakers in learning more about each other, which relates to the fourth research question. Some participants also changed their communication to appear respectful and more understanding of the other speaker. For that reason, as mentioned regarding the last question, some participants stated that they slowed down their communication. This, then, implies that communication is clearly altered when speakers of different racial groups communicate. The findings from participants and the media regarding postcolonialism suggest that organizations have the colonial habit to racially stereotype non-White people in the news projecting a negative view that can only generate false perceptions of other ethnic groups. The type of action made by news organizations then resembles how people in power ignore the common problems in racism and stereotyping (PittRivers, 1967). Another example of the postcolonial mentality of the news organizations came from most of the participants' answers saying that not just news outlets but television shows and other forms of the media make non-Whites seem not as important and create labels, which then only leaded to the mistrust of the participants to the media.

Each research question had certain themes, the first dealing with how participants described their identity. The importance of identity was for participants to understand what ethnic group they identified with which helps in understanding the stereotypes that exist among different ethnic groups (Dixon, 2006). Participants gave answers explaining their identity, which can help readers understand the different ways participants perceived their identity, such as in 
terms of physical traits, nationality, race, or language. The purpose of the second research question was to find if postcolonial behavior was present in media, particularly Western media. The answers provided understanding that there was a certain bias that participants felt was being emulated by news organizations. Participants' answers related to the previous literature regarding how news outlets were overly concerned with representation and race regarding identity (Cere, 2011). The purpose of the third research question was to see if people changed their communication. The answers clarified whether postcolonial thoughts may have been present for the participants. Evidence from the literature review had shown participants changing their communication based on the other ethnic speaker (Gasiorek \& Giles, 2012). In addressing the fourth question, the answers showed that participants would change their communication but in order to accommodate the other's communication and not due to having postcolonial mindsets. The results mean that people change their communication but as mentioned earlier, do so to increase closeness with the speaker. The participants showed a desire to converge to the speaker so that they could accommodate the other speaker's communication (Gileset al., 1991).

Another speaker who had preconceived notions about other ethnic groups suggested that such notions impacted her communication choices:

Like many others, I also have preconceived assumptions about other ethnic groups. It's a matter of trying to look past your presumptions and taking that other person at face value. A Caucasian person, for example, I would perceive as being more sensitive to certain topics or more condescending. These are things I don't want to think or believe are true, but it's more of a product of my upbringing. 
As mentioned earlier, the participant explained his preconceived assumptions in terms of his upbringing, as most participants were likely raised in ways to believe people act in certain behaviors because of different cultures.

\section{Implications}

\section{Theoretical Implications}

In the view of the results, it is important to look at the implications for media and changes of communication towards other ethnic speakers and how the findings relate to postcolonialism and communication accommodation. Firstly, people are aware of their own identity when speaking with others from different ethnic groups. For example, people are aware of their own ethnic differences when speaking to someone else of a different race, with one participant saying: "I ethnically distinguish myself from others I perceive as different by the country we both are from, our first languages, perhaps if we look differently, or if our accents differ."

Secondly, communication between speakers of different ethnicities changes, according to the participants' self-reports, but only in terms of accommodating communication to the other speakers. Media representation plays an important role in creating social categorizations and perceptions of other racial groups, particularly in the United States. For example, one response from a participant was, "Many media outlets like to use ethnically different people as either scapegoats or reasons to push their own agenda," which revealed that some participants feel that the media may take on views that scrutinize certain ethnic groups like Blacks and Hispanics. Participants expressed a mostly negative view towards news outlets; others accused some news outlets of representing racism through stereotyping, while the results of the findings suggest that non-Whites are represented in a negative light thanks to poor media representation of other ethnic groups. Many viewers can hold these biased views towards ethnic groups due to the 
negative coverage as described from participants. The critical response from the participants showed their distrust towards news outlets in the media. The results reflect the findings of Dixon (2006), as most participants in the study were aware of the stereotypes of other minorities by branches of the media like news outlets.

Postcolonial theory. Postcolonial theory explores how literature produced in countries is or was affiliated at one time, with colonialism (Said, 1978) and extends to the ways that colonial histories impact the lives and communication of individuals (Shome \& Hedge, 2002). The results from the study suggest that many people in news organizations may harbor some colonial attitudes. The findings support postcolonialism because there continue to be people that categorize and stereotype other racial groups in terms of objectification and demonizing nonWhite people, which strongly relates to having a colonial mindset.

The residue in non-postcolonial countries, for example, European countries, is still relevant. As discussed in the literature review, social barriers continue to exist between Whites and Blacks. As mentioned by Dixon and Rosenbaum (2004), social barriers for Blacks was due to colonization and the creating the mindset that Blacks were essentially not on par with their White counterparts. That being said, the extended residue seems to remain in non-postcolonial countries as not only people, but media outlets show white skin as being purer and likeable while having dark skin was seen as being more unattractive, at least as participants describe those outlets. The idea that residue left in non-postcolonial countries remains, particularly among people of color in Western countries, reflects previous literature (Stepler,2016) showing how Blacks and other groups are still widely discriminated against as equal quality for not just Blacks but all minority groups has yet to be established. 
While most of the findings did not relate to postcolonialism, there were some instances in media that did resemble postcolonial actions. First, participants state that news outlets, from television to the Internet, show only one side of an ethnic group, often the negative side. This can create distrust on the part of the participants. Many participants stated that outlets in the media would scrutinize certain ethnic groups thus creating the uneasiness and trust between the participants and the news outlets. One participant asserted that news outlets in the media have commonly sided with one ethnic group over another in showing negative coverage of non-White ethnic groups in hopes of increasing viewer popularity. Studies regarding racial inequality relate negative racial representation to colonialism (Sommers, Apfelbaum, Dukes, Toosi, \& Wang 2006). Specifically, participants believed that many media outlets followed an agenda that did not appear to be in favor of covering other ethnic groups in a positive light, which maintains White power within society. One participant mentioned that movies also portray Whites as being intelligent and rich while casting Blacks as being dangerous and poor and Asians as being rich and smart, therefore showing that racial categorization of media outlets appears to continue from colonial times.

Third, according to Postcolonial theory, these news outlets reflect the actions and footsteps of colonialism in labeling other racial groups negatively (Lazarus, 2002). This study shows that participants believe that the messages from biased news outlets create resentment that people, like the participants, have towards the media. The arguments made by many participants best connected with Hall's (2007) argument that people of color are still silenced by news outlets and other organizations in the media, which then allow Whites to speak for them. The participants perceive that the media do, in fact, have power on their viewers in terms of racial criticism along with exerting power over other ethnic groups. 
The link to postcolonialism is that, when speaking with others of different ethnic groups, the participants described the actions of news organizations and their stereotypes and labels put upon non-White groups. Postcolonialism hence refers to the lingering effects of what colonial actions were placed upon non-White groups thus showing the residue of postcolonialism in the media. Postcolonial residue affecting non-colonized countries can simply be in the form of racism where the labels placed on Blacks and Indigenous people is likely negative. As mentioned in one study (Stepler, 2016), Blacks still feel that there is still an unequal balance of equality compared to their White counterparts. This suggests that when Blacks are often pulled over by the police more often than White drivers, this likely stems from the residue of postcolonialism and the fact that the label placed on Blacks during colonial times affects them to the present day.

According to Wasserman (2006), influences on media like news outlets are primarily Western, as reflected in the results, where most of the participants explain that many racial groups that are not Western-like are portrayed in a negative light. Face-to-face communication reflects this when people are careful when speaking with people of different races of to avoid certain political subjects. In this case, media representation connects with face-to-face communication in different societies (Entman \& Rojecki, 2001), as it portrays how ethnic groups are aware of sensitive issues when communicating with one another. This example demonstrates the power of Western media. This study shows that while news outlets in the media are seen to express racial bias, viewers are becoming more aware of the problems stemming from certain news outlets in the media. Reporters in news outlets reflect colonial attitudes as far as categorizing those that were not White (Gunew, 1997). Participants imply that media outlets demonize certain racial groups: One participant mentioned how many minority groups in the United States are ostracized by news outlets in the media. In addition to the study, the 
participants' highlighting of the media's addiction to representation and stereotyping other racial groups (Cere, 2011) has postcolonial relevance, as the media displays more positive images of Whites over other races in Western countries (Alhassan \& Chakravartty, 2011). In their descriptions of the influences of the media, participants describe how the media represented certain ethnic groups in a problematic way (Plasa, 2000), which relates to postcolonialism and how the media frame ethnic groups that are not White as troublesome.

At the same time, postcolonialism may not relate to participants' own views of ethnic identity, as some participants viewed other ethnic speakers as just normal speakers without creating ethnic labels during communication. The third-person media effect (Davison, 1983) could explain why participants gave their answers on media questions, in that people believed that media affect other people but not themselves. Traces of postcolonialism may also affect the participants because of how news outlets in the media affect their treatment to different ethnic speakers beyond their own moral thinking (Waters, 1992). Media, then, may relate to the participants' communication because of the images and messages that they relay to participants on how they may behave towards different ethnic speakers.

Communication between speakers, while changed, is changed for reasons as to appear politer to the other speaker. However, this sort of communication may still demonstrate traces of postcolonialism because there were participants that stated they would still change their communication based on someone of a different ethnicity without stating whether the other speaker could have been of the same nationality. This reveals the inherent changes that people are likely to make in their communication based on the appearance of someone else regardless of whether the other speaker is of the same nation. However, while there were no traces of postcolonial behaviors in the participants' comments about their own behavior, future research 
could show that the racial demonization that news outlets make of other minority groups could generate a postcolonial mindset, as participants did mention the racial divisiveness that certain news outlets previewed.

Communication Accommodation Theory. CAT posits that people will accommodate their communication towards or away from another speaker (Gasiorek \& Vincze, 2016). The results of the study support the theoretical assumption because the participants described how their communication did in fact change while speaking with people of different races. Participants reported changing their behavior in a variety of ways including speaking at slower rates or changing how they would normally speak when speaking to other ethnic speakers.

CAT explores the reasons as to why people may change their communication between speakers and how people accommodate towards or away from another speaker's communication. The theory suggests that people sometimes overaccommodate to others' communication by slowing down their speaking to appear more understanding and respectful. Participants in the present study may also have believed that they were converging appropriately, but the other speaker may not agree in terms of over- or underaccommodation (Giles et al., 2003). In this study, some participants stated that they change their communication upon speaking with someone of a different racial background, but there were no signs in the results of people underaccommodating. It might be that participants are not aware of any underaccommodation. One criticism of these findings would be, when speakers change their communication, that the other speaker may be not only racially but culturally different. To clarify, people may adjust to perceived language communication and language differences between certain cultural groups when they believe there are differences in groups when in fact, there were none (Baldwin, Coleman, González, \& Shenoy-Packer, 2014). 
While many of the participants did not see their changes in speaking behaviors as negative, Giles et al. (1991) assert that changing speaking behaviors could lead to having other speakers feeling more insulted. One participant, for example, stated that he tried to change his communication to be like that of the other speaker, but later confirmed it was offensive. The speaker immediately spoke the way he normally would, maintaining his communication style. Accommodation was shown to be in effect, in that participants adjusted their communication and often converged to different ethnic speakers. One speaker stated that, based on the ethnicity of the other speaker, he would converge to the other speaker to appear more comforting, rather than diverge away from a speaker. Most participants in the study reported converging to someone's communication than diverge in most situations.

Speakers did not mention signs of overaccommodating or underaccommodating in terms of changing too much or too little in their communication with speakers of other ethnicities. Participants described making what they saw as the right amount of changes in their communication with other ethnic speakers, not stating if they had been over or under accommodating. Participants may have tried to alter their speaking behavior to appear more respectful to not appear being underaccommodative towards the other speaker. Some speakers also stated that their communication did not change at all, possibly trying to avoid appearing over- or underaccommodative altogether.

A linkage to CAT would be that the participants revealed adjusting their communication to properly accommodate the other ethnic speaker's communication. White participants may have mostly changed their communication to other ethnic speakers because of the racial population of the United States and the fact that Whites make up a majority of the population. Black participants described adjusting their communication to other speakers of the same ethnic 
group. A Black participant mentioned changing communication with White participants, converging to the White speaker's communication for acceptance and hoping to feel more professional.

The results showed that participants were more likely to converge to another speaker's communication when are they are in the same ethnic group or for group acceptance. The communication from participants demonstrated communicating with others of different ethnic groups change but to converge to another speaker to increase comfort and group belonging. The communication between participants showed that the speakers intended to increase their social distance with the other speaker (Gasiorek \& Vincze 2016). The desire to converge while not reflecting traces of postcolonialism reveals that participants may not have had a colonial mindset, as earlier anticipated.

\section{Strengths, Limitations and Directions for Future Research}

\section{Strengths and Limitations}

This thesis will serve as initial research in exploring speaking behaviors among different ethnic groups understood through a postcolonial lens. One of the strengths of the study was the involvement of the 135 participants, which provided enough data as I found many results in accordance with the study. I collected information to reveal common communication behaviors that relate to postcolonial mentalities such as whether people categorize others into ethnic groups. In addition, this study was special as the participants could give critical thought into how

they may not have realized changes when communicating with others prior to taking the survey.

Studies regarding postcolonial behaviors dealt with negative experiences but most responses did not reflect the postcolonial attitudes that were previously documented in racial thoughts. The present study is unique because it reveals that participants are aware of ethnic 
identity in their communication. Postcolonial attitudes were not present, but participants did mention the actions of people in news organizations that resemble postcolonial actions in terms of racial categorization. Future research should investigate whether people see their communication adjustment in terms of ethnic differences or cultural differences when interacting with international students, as well as how international students perceive their adjustment to U.S. nationals either in cultural or ethnic terms. A possible reflection of colonial attitudes could be that people adjust their communication out of respect for the other ethnic speaker, but that such adjustment could, in fact, ensure that the dominant, White U.S. communication style remains. Regardless, the present study could not determine colonial mentalities directly because participants were not aware of the changes or how they were perceived (Giles et al., 2003). The responses from most participants about the negativity and racial categories created by media outlets suggests that colonialism still affects western thinking despite democratic progression in trying to alleviate such problematic symptoms. These studies, hence, suggest how powerful postcolonialism may be in terms of creating tribal mentalities of group identification and changes in speaking behaviors,

While postcolonialism was not clearly present in the findings of participant reports of changes in their behavior, such changes might show one ethnic speaker being labeled or discriminated against in some form of racism. Postcolonial behavior would have likely shown how people perceive others negatively because they are of a different ethnic group, which was not reported in the comments from the participants from any race. People in media, however, could have likely demonstrated postcolonialism, as the participants mentioned several ways news organizations and other various media outlets place labels on non-White groups and view them 
only with a negative perception. The issues with people in news organizations could then likely lead to future research as to why people create labels for non-White ethnic groups.

While the study had strengths, some noteworthy limitations are also apparent. The first limitation was the limited number of participants taking the survey. The number of participants was sufficient for taking the survey, leading to redundancy in thematic development; however, overall there could have been more participants to gather better results and perhaps develop richer categories. The fact that only Midwestern students at certain age groups participated could have led to a limited range of responses due to the participants living in similar environments. If there would have been more surveys taken by others around the United States, then there could have been more diverse results.

Several response biases may have impacted the study. First, participants may have felt that questions were too direct and thus not provided an honest answer to the survey, reflecting a social desirability bias. Social desirability may also have impacted the study as participants may have felt inclined to answer questions in a particular way due to the language of the question. A participant could have felt that his or her race may have been targeted as a sample for the study, and therefore given false answers to represent her or his race well.

Non-distinction between races also may have hindered the study as many participants may have not looked at race as being of importance. It is possible that the participants did not differentiate between notions like race, ethnicity, or culture when responding to the survey. Clearer instructions may have been more helpful in their self-identification when taking the survey, as some participants were unsure at first how to address the second question of the survey. 
Another limitation would be possible memory effect, because the survey asked participants to recall times when speakers had their last conversation with someone from a different ethnic background. It is possible that they did not remember how they communicated or, in fact, if they were aware of changes that they did or did not make in the interaction. Leets, Giles, and Noels (1999), for example, note how some people are not aware of the changes they make. Participants were likely not able to describe every detail of their encounter, which could have been crucial for collecting pertinent information. These limitations then relate to whether the participants were honest with their answers due to possibly feeling uncomfortable with the questions or simply wishing to advance through the study without thinking critically. Many participants also described not changing communication behaviors at all, so different questions about previous encounters with other speakers could have benefited the study.

Having participants that may have come from a marginalized group may have better demonstrated postcolonial behaviors when speaking with others from different ethnic groups. However, the marginalized groups might be less willing to describe their experiences with others as they might be tired of talking about racial or other types of oppression. The marginalized groups may describe their communication as being bad as a form of being intolerant of the dominant ethnic group. Social desirability bias could have also lead for participants to answer the questions in a particular way that may not have benefited the study.

\section{Future Research}

There are many opportunities for future research, such as more exploration as to why people change their communication and perhaps further investigation into colonial effects that continue within communication. Postcolonialism itself still has not been fully researched in terms of finding out why people may speak differently in intergroup or intercultural interaction. 
In postcolonial times, images in the media continue to have an effect on people, creating a mindset in which Whiteness rules over those considered Non-White or "third world" (Shome, 1996). The present study exposed the sorts of changes in behaviors created by speakers when communicating with people of different races, through few participants stated explicitly that it was because of race or ethnic differences that they communicated differently. As previously mentioned, speakers may not even catch themselves speaking differently to people of different ethnic backgrounds. Examining the link between postcolonialism and race, then, will likely yield more information on people and their social behaviors towards others. The participants in this study mentioned having peaceful intentions for the changes in their communication when speaking with speakers of other ethnicities. Researchers may benefit by seeking participants who may have had more negative experiences with people of different ethnic backgrounds to find any postcolonial evidence. It is still necessary to examine recent conversations that speakers may have had with differently ethnic people to fully understand why people behave differently in their communication. As mentioned previously, one participant stated feeling more secure when speaking with people of the same race than others in relating to culture and region, signaling that college students could revert to creating negative stereotypes when communicating with different ethnic speakers (McKenna \& Sauceda, 2001). The need also extends to looking at communicative behavior because participants were not aware of the changes they made when they adjusted their communication with different ethnic speaker; ethnographic or experimental research may also be necessary in future studies.

This study demonstrates the importance of examining racial relations as they relate to changes in communication. As communities become more diverse, the possibility of changes within communication will become more apparent. More research would, then, become useful to 
better understand changes people make when encountering ethnically different speakers. A quantitative study may be beneficial to obtain results at a quicker pace and to more clearly show quantitative relationships. The present study showed that the media may influence people to speak and act differently when encountering people of different ethnicities. As many of the participants mentioned, much of the media in American society is biased and often represents people of color stereotypically. The result from the influence of news outlets, specifically, has created a distrust among many people who oppose news outlets' negative portrayal of ethnic minorities. Researchers may benefit from open-ended questions as participants are able to describe in full detail their experiences of communicating with speakers from other groups. Due to an ever-changing demographic in Western countries, particularly the United States, more research will be needed to properly document human reactions to change and how and when they will change their behavior to ethnically different people.

Connections to the review of literature revealed that there was a definite problem when it came to news organizations and non-White groups because of racism. As previous research (Strongman, 2014), linked that postcolonialism has thrived throughout the passing centuries and still hindering non-White people in terms of racial discrimination. Media organizations described in the literature review then had the problem of labeling and carrying on the stereotyping that was implemented during colonial times. The links to the literature review did show that, even if people do not change their communication because of a postcolonial mindset, colonialism may still impact the actions of western media organizations.

In terms of the changing demographics of Western society, communication between others has remained the same despite a large decline in a homogenous group. Changing demographics will likely impact whether people will adjust their speaking behaviors over time. 
Changing demographics, hence, suggest that Whites have likely made more changes in their communication with others than in previous generations due to a greater number of non-White speakers. The changes however, are likely made more by non-White speakers because of the majority of Whites in the country and the style of communication that remained dominant. It may be that the increased change in demographics could lead to a different direction in terms of speaking behaviors because of increased exposure to other cultures such as mentioned earlier in the document showing a large increase in Hispanic and Asian populations. That is, as the population becomes more diverse, communication adjustment might become either less prevalent or more multi-directional. At the same time, even in a multicultural society like the United States, the speaking patterns stemming from communication may remain the same due to their being cultural norms in a western society. The effects of a dominant power structure from Whites has molded communication styles for all ethnic speakers and is likely to continue; even though the hegemonic power may be in decline, the linguistic effects will likely continue to remain.

\section{Summary}

This study reveals the overall human behavior of how people of different races communicate with one another in terms of changes in communication. The study showed that participants used selectivity in communicating with other races, changing their behavior depending on the cultural identity of the communication partner, though there was not enough evidence to show that postcolonial attitudes were as prevalent as previously believed. Not only does the project provide new information about this topic, but it gives more reason to further research the changes that happen in conversations in schools, communities, and the workplace. This topic is important as changing demographics will likely trigger changes in personalities and 
behaviors. The change in demographics will likely create the need for using CAT to better understand an impending population shift and how people communicate considering these changes. The results from this study should only be the first step in understanding how people will eventually have to adjust their communication within a racially changing society. 


\section{REFERENCES}

Acemoglu, D., \& Robinson, J. A. (2017). The economic impact of colonialism. In S. Michalopoulos \& E. Papaioannou (Eds.), The long economic and political shadow of history (Vol. 1, pp. 81-87). New York, NY: VOX e-book

doi:81.10.1080/01436597.2014.946248

Alhassan, A., \& Chakravartty, P. (2011). Postcolonial media policy under the long shadow of empire. In R. Mansell, \& M. Raboy (Eds.), The handbook of global media and communication policy (pp. 372-373). Hoboken, NJ: Wiley-Blackwell.

Amato, S. (2009). The white elephant in London: An episode of trickery, racism and advertising. Journal of Social History, 43, 31-66. doi:10.1353/jsh.0.0234

Baker, M. A. (1991). Reciprocal accommodation: A model for reducing gender bias in managerial communication. Journal of Business Communication, 28(2), 113-130. doi: $10.1177 / 002194369102800203$

Baldwin, J. R., Coleman, R. R. M., González, A., \& Shenoy-Packer, S. (2014). Intercultural communication for everyday life. Malden, MA: Wiley-Blackwell Publishing.

Bhambra, G. (2007). Rethinking modernity: Postcolonialism and the sociological imagination. New York, NY: Springer.

Bourhis, R. Y., Sioufi, R., \& Sachdev, I. (2012). Ethnolinguistic interaction and multilingual communication. In H. Giles (Ed.), The handbook of intergroup communication (pp. 100115). New York, NY: Routledge.

Calas, M., \& Smircich, L. (1996). From the woman's point of view: Feminist approaches to organization studies. In S. R. Clegg, C. Hardy, \& W. Nord (Eds.), Handbook of organization studies (pp. 218-257). Thousand Oaks, CA: Sage. 
Cere, R. (2011). Postcolonial and media studies: A cognitive map. In C. Rinella \& R. Brunt, (Eds.), Postcolonial media culture in Britain (pp. 1-13). Basingstoke, UK: Palgrave Macmillan.

Césaire, A. (2000). Discourse on colonialism. New York, NY: NYU Press.

Chan, J. M., \& Lee, F. L. (2010). Media, social mobilisation and mass protests in postcolonial Hong Kong. New York, NY: Routledge.

Christopher, A. (1983). From Flint to Soweto: Reflections on the colonial origins of the apartheid city. Area, 15(2), 145-149. Retrieved from http://www.jstor.org/stable/20001914

Cohn, D., \& Caumont, A. (2016). 10 demographic trends that are shaping the U.S. and the world. Pew Research Center. Retrieved from http://www.pewresearch.org/facttank/2016/03/31/10-demographic-trends-that-are-shaping-the-u-s-and-the-world/

Colby, S., \& Ortman, M. (2015). Projections of the Size and Composition of the U.S. Population: 2014 to 2060. Current Population Reports. 125-1143. Retrieved from: https://www.census.gov/content/dam/Census/library/publications/2015/demo/p251143.pdf

Cooper, L. A., Roter, D. L., Carson, K. A., Beach, M. C., Sabin, J. A., Greenwald, A. G., \& Inui, T. S. (2012). The associations of clinicians' implicit attitudes about race with medical visit communication and patient ratings of interpersonal care. American Journal of Public Health, 102, 979-987. doi:10.2105/AJPH.2011.300558

Cortese, A. J. (1999). Provocateur: Images of women and minorities in advertising. Contemporary Sociology, 30(2), 125-165. doi:10.2307/2655405 
Davison, W. P. (1983). The third-person effect in communication. Public Opinion Quarterly, 47(1), 1-15. doi:10.1086/268763

De Almeida, M. (2002). Longing for oneself: Hybridism and miscegenation in colonial and postcolonial Portugal. Oeiras, Portugal: Celta.

Dirks, N. B. (1992). Colonialism and culture. Ann Arbor, MI: University of Michigan Press.

Dixon, T. L. (2006). Psychological reactions to crime news portrayals of Black criminals: Understanding the moderating roles of prior news viewing and stereotype endorsement. Communication Monographs, 73(2), 162-187. doi:10.1080/03637750600690643

Dixon, J. C., \& Rosenbaum, M. S. (2004). Nice to know you? Testing contact, cultural, and group threat theories of anti-Black and anti-Hispanic stereotypes. Social Science Quarterly, 85(2), 257-280.

Entman, R., \& Rojecki, A. (2001). The Black image in the White mind: Race and media in America. Chicago, IL: University of Chicago Press.

Fernandez, M. (1999). Postcolonial media theory. Art Journal, 58(3), 58-73. doi: 10.1080/00043249.1999.10791954

Fiehrer, T. (1979). Slaves and freedmen in colonial Central America: Rediscovering a forgotten Black past. Journal of Negro History, 64(1), 39-57. doi:10.2307/2717125

Frisby, C. (2017). Does race matter? Effects of idealized images on African American women's perceptions of body esteem. Journal of Black Studies, 34(3), 323-347.

Frith, K. T., Cheng, H., \& Shaw, P. (2004). Race and beauty: A comparison of Asian and Western models in women's magazine advertisements. Sex Roles, 50(1), 53-61. 
Gasiorek, J., \& Giles, H. (2012). Effects of inferred motive on evaluations of nonaccommodative communication. Human Communication Research, 38, 309-331. doi: 10.1177/0261927X12446614

Gasiorek, J., \& Giles, H. (2013). Communication, volunteering, and aging: A research agenda. International Journal of Communication, 7, 2659-2677. Retrieved from: http://ijoc.org/index.php/ijoc/article/view/1774/1037

Gasiorek, J., \& Giles, H. (2015). The role of inferred motive in processing nonaccommodation: Evaluations of communication and speakers. Western Journal of Communication, 79, 456-471. doi:10/1080/10570314.2015.1066030

Gasiorek, J., \& Vincze, L. (2016).Modeling motives for bilingual accommodation by minority and majority language speakers. Journal of Language and Social Psychology, 35, 305316. doi:10.1177/0261927X15605144

Giles, H., Coupland, N., \& Coupland, J. (1991). Accommodation theory: Communication, context, and consequence. In H. Giles, J. Coupland, \& N. Coupland (Eds.), Contexts of accommodation: Developments in applied sociolinguistics (pp. 1-68). Cambridge: Cambridge University Press. doi:10.1017/cbo9780511663673.001

Giles, H., Linz, D., Bonilla, D., \& Gomez, M. L. (2012). Police stops of and interactions with Latino and White (Non-Latino) drivers: Extensive policing and communication accommodation. Communication Monographs, 79, 407-427. doi: $10.1080 / 03637751.2012 .723815$ 
Giles, H., Noels, K. A., Williams, A., Ota, H., Lim, T. S., Ng, S. H., \& Somera, L. (2003). Intergenerational communication across cultures: Young people's perceptions of conversations with family elders, non-family elders and same-age peers. Journal of Cross-cultural Gerontology, 18(1), 1-32. doi:10.1023/A1024854211638

Golnaraghi, G., \& Mills, A. J. (2013). Unveiling the myth of the Muslim woman: A postcolonial critique. Equality, Diversity and Inclusion: An International Journal, 32, 157-172. doi: $10.1108 / 02610151311324398$

Gunew, S. (1997). Postcolonialism and multiculturalism: Between race and ethnicity. In A. Gurr (Ed.), The yearbook of English studies 27 (pp. 22-39). Chicago, IL: Maney \& Son.

Hall, M. L. (2007). The postcolonial Caribbean as a liminal space: Authoring other modes of contestation and affirmation. Howard Journal of Communications, 18(1), 1-13. doi:10.1080/10646170601147432

Ivison, D. (2015). Indigenous peoples, injustice and global politics. In B. Buckinx, J. TrejoMathys, \& T. Waligore (Eds.), Domination and global political justice: Conceptual, Historical and institutional perspectives (pp. 206-223). New York, NY: Routledge.

Imre, A. (2014). Postcolonial media studies in postsocialist Europe. Boundary 2, 41(1), 113-134. doi:10.1215/01903659-2409694

Iyengar, S., \& Barisione, M. (2015). Non-verbal cues as a test of gender and race bias in politics: The Italian case. Italian Political Science Review, 45(2), 131-157. doi: 10.1017/ipo.2015.9

Jakobson, R., \& Halle, M. (2002). Fundamentals of language. Amsterdam, Netherlands: North Holland Publishing Company. 
Jaimes, M. A. (1992). The state of Native America: Genocide, colonization, and resistance. Boston, MA: South End Press.

Klein, A. (1983). The political-economy of gender: A 19th century plains Indian case study. In P. Albers, \& B. Medicine (Eds.), The hidden half: Studies of plains Indian women (pp. 143173). New York, NY: University Press of America.

Krysan, M., \& Moberg, S. (2016, August 25). Trends in racial attitudes. University of Illinois Institute of Government and Public Affairs. Retrieved from: http://igpa.uillinois.edu/programs/racial-attitudes

Lange, M., \& Dawson, A. (2009). Dividing and ruling the world: A statistical test of the effects of colonialism on postcolonial civil violence. Social Forces, 88, 785-817. doi: $10.1353 /$ sof.0.0255

La Cadena, M. D. (2001). Reconstructing Race: Racism, culture and mestizaje in Latin America. NACLA Report on the Americas, 34(6), 16-23. doi:10.1080/10714839.2001.11722585

Lazarus, N. (2002). The fetish of "the West" in postcolonial theory. In C. Bartolovich, \& N. Lazarus (Eds.), Marxism, modernity and postcolonial studies, (pp. 43-64). Cambridge, UK: Cambridge University Press.

Leets, L., Giles, H., \& Noels, K. (1999). Attributing harm to racist speech. Journal of Multilingual and Multicultural Development, 20(3), 209-215. doi:10.1080/01434639908666377

Lemkin, R. (1944). Axis rule in occupied Europe: Laws of occupation, analysis of government, proposals of redress. Washington, DC: Carnegie Endowment for International Peace. 
Linnemann, G. A., \& Jucks, R. (2016). As in the question, so in the answer? Language style of human and machine speakers affects interlocutors' convergence on wordings. Journal of Language \& Social Psychology, 35, 686-697. doi:10.1177/0261927X15625444

Loomba, A. (2015). Colonialism/postcolonialism: The new critical idiom. New York, NY: Routledge.

Mamdani, M. (1996). Citizen and subject: Contemporary Africa and the legacy of late colonialism. Princeton, NJ: Princeton University Press.

Marker, S. (2003, November). The effects of colonization. Beyond intractability, Retrieved from http://www.beyondintractability.org/essay/post-colonial.

McClintock, A. (1992). The angel of progress: pitfalls of the term "Post-Colonialism" social text. Third World and Post-Colonial Issues, 31-32, 84-98. doi:10.2307/466219

McDonnell, M. A., \& Moses, A. D. (2005). Raphael Lemkin as historian of genocide in the Americas. Journal of Genocide Research, 7, 501-529. doi:10.1080/14623520500349951

McKenna, J. H., \& Sauceda, J. M. (2001). Students talk about race. In D. Schoem, \& S Hurtado (Eds.), Intergroup dialogue: Deliberative democracy in school, college, community, and workplace (pp.74-84). Ann Arbor, MI: The University of Michigan Press.

Mishra, R. K. (2013). Postcolonial feminism: Looking into within-beyond-to difference. International Journal of English and Literature, 4(4), 129-134. doi:10.5897/IJEL12.165

Mohanty, C. T., Russo, A., \& Torres, L. (1991). Third world women and the politics of feminism. Bloomington, IN: Indiana University Press.

Mountain, A. (2003). The first people of the Cape: A look at their history and the impact of colonialism on the Cape's indigenous people. Claremont, South Africa: New Africa Books. 
Nast, H. J. (2000). Mapping the "unconscious": Racism and the oedipal family. Annals of the Association of American Geographers, 90, 215-255. doi:10.1111/0004-6508.00194

Pew Research Center. (2016, June 27). On views of race and inequality, Blacks and Whites are worlds apart. Social \& demographic trends. Retrieved from http://www.pewsocialtrends.org/2016/06/27/on-views-of-race-and-inequality-blacks-andwhites-are-worlds-apart/

Pitt-Rivers, J. (1967). Race, color, and class in Central America and the Andes. Daedalus, 6, 542-559. Retrieved from http://www.jstor.org/stable/20027052

Pitts, M. J., \& Harwood, J. (2015). Communication accommodation competence: The nature and nurture of accommodative resources across the lifespan. Language \& Communication, 41, 89-99. doi:10.1016/j.langcom.2014.10.002

Plasa, C. (2000). Charlotte Brontë's foreign bodies: Slavery and sexuality in the professor. Journal of Narrative Theory, 30, 1-28. doi:10.1353/jnt.2011.0013

Rice, R. E., \& Giles, H. (2017). The contexts and dynamics of science communication and language. Journal of Language and Social Psychology, 36, 127-139. doi:

\section{$0.1177 / 0261927 X 16663257$}

Ruiz, M. I. R. (2012). Black states of desire: Josephine Baker, identity and the sexual Black body. Revista de Estudios Norteamericanos. Retrieved from http://institucional.us.es/revistas/estudios/16/art_8.pdf

Said, E. (1978). Orientalism: Western concepts of the Orient. New York, NY: Penguin Books.

Said, E. W. (1986). Intellectuals in the post-colonial world. Salmagundi. Retrieved from http://www.jstor.org/stable/40547786 
Salvatore, R. D. (2010). The postcolonial in Latin America and the concept of coloniality: A historian's point of view. A Contra Corriente: A Journal on Social History and Literature in Latin America. Retrieved from https://acontracorriente.chass.ncsu.edu/index.php/acontracorriente/article/view/496/767

Schulman, K. A., Berlin, J. A., Harless, W., Kerner, J. F., Sistrunk, S., Gersh, B. J., \& Eisenberg, J. M. (1999). The effect of race and sex on physicians' recommendations for cardiac catheterization. New England Journal of Medicine, 340, 618-626. doi: 10.1056/nejm199904083401424

Settles, J. D. (1996). The impact of colonialism on African economic development (Unpublished master's thesis). Retrieved from http://trace.tennessee.edu/cgi/viewcontent.cgi?article=1182\&context=utk_chanhonoproj

Shome, R. (1996). Race and popular cinema: The rhetorical strategies of whiteness in City of Joy. Communication Quarterly, 44(4), 502-518. doi:10.1080/01463379609370035

Shome, R., \& Hedge, R. S. (2002). Postcolonial approaches to communication: Charting the terrain, engaging the intersections. Communication Theory, 12, 249-270. doi: $10.4135 / 9781446262085$

Singh, P., \& Rampersad, R. (2010). Communication challenges in a multicultural learning environment. Journal of Intercultural Communication, 23, 1404-1634. Retrieved from https://www.immi.se/intercultural/nr23/singh.htm

Sommers, S. R., Apfelbaum, E. P., Dukes, K. N., Toosi, N., \& Wang, E. J. (2006). Race and media coverage of Hurricane Katrina: Analysis, implications, and future research questions. Analyses of Social Issues and Public Policy, 6, 39-55. doi:10.111/j.15302415.2006.00101.x 
Stepler, R. (2016). 5 key takeaways about views of race and inequality in America. Pew Research Center. Retrieved from http://www.pewresearch.org/fact-tank/2016/06/27/keytakeaways-race-and-inequality/

Strongman, L. (2014). Postcolonialism and international development studies: A dialectical exchange? Third World Quarterly, 35, 1343-1354. doi:10.1080/01436597.2014.946248

Stuchtey, B. (2011). Colonialism and imperialism, 1450-1950. European History Online (EGO). Retrieved from http://www.ieg-ego.eu/stuchteyb-2010-en

Syed, J. (2007). The other woman and the question of equal opportunity in Australian organizations. International Journal of Human Resource Management, 18, 1954-1978. doi:10.1080/09585190701638184

Telles, E., \& Paixão, M. (2013). Affirmative action in Brazil. Lasa Forum, 44(2), 10-12. Retrieved from http://www.soc.ucsb.edu/faculty/telles/uploads/8/7/5/2/87525260/2013_affirmative_actio n_in_brazil-lasa_forum.pdf

Tuch, S. A. (1987). Urbanism, region, and tolerance revisited: The case of racial prejudice. American Sociological Review, 52(4), 504. doi:10.2307/2095295

Tyagi, R. (2014). Understanding postcolonial feminism in relation with postcolonial and feminist theories. International Journal of Language and Linguistics, 1(2), 45-50. Retrieved from http://www.ijllnet.com/journals/Vol_1_No_2_December_2014/7.pdf

United States Census Bureau. (2015). New Census Bureau Report Analyzes U.S. Population Projections. Retrieved from https://www.census.gov/newsroom/pressreleases/2015/cb15-tps16.html 
Villarreal, A. (2010). Stratification by skin color in contemporary Mexico. American Sociological Review, 75, 652-678. doi:10.1177/0003122410378232

Waters, H. (1992). Race, culture and interpersonal conflict. International Journal of Intercultural Relations, 16, 437-437. doi:10.1016/0147(92)90032-P

Wasserman, H. (2006). Globalized values and postcolonial responses: South African perspectives on normative media ethics. International Communication Gazette, 68(1), 71 91. doi: $10.1177 / 1748048506060116$

Watson, I. (2009). Aboriginality and the violence of colonialism. Borderlands E-journal, 8(1), Retrieved from https://ssrn.com/abstract=2476792

White, O. (1999). Children of the French Empire: Miscegenation and colonial society in French West Africa 1895-1960. New York, NY: Clarendon Press.

Young, R. (2016). Postcolonialism: An historical introduction. New York, NY: WileyBlackwell. 


\section{APPENDIX: SURVEY INSTRUMENT}

\section{Survey Instrument}

Demographic information

1. How do you identify?

Male

Female

Other [space will be provided to fill in an answer should participants chose to do so]

Prefer not to disclose

2. How old are you?

3. Please select the following racial identities with which you identify:

_ White/Caucasian (non-Hispanic)

H Hispanic/Latino

Black

Native-American

_ East Asian

Pacific Islander

South Asian

Middle Eastern

Mixed Race

Other [space will be provided to fill in an answer should participants chose to do so Prefer not to disclose

4. In what ways do you ethnically distinguish yourself from others you perceive as different?

5. Describe the way(s) in which you tend to communicate with someone you perceive as ethnically different.

6. When speaking with different ethnicities, how does your way of speaking change, if at all?

7. If viewing or involved with a negative situation with someone of a different race, how did your perception change of the people of that ethnicity, if at all?

8. How do you feel that media tend to describe people you view as ethnically different? For example, what if.

For the last section, please think of the most recent times you have encountered and adjust your communication while talking with someone that is ethnically different than you.

9. In what specific ways did you change your communication?

10. Why do you think you changed the way you spoke? 
11. What may have influenced you in speaking the way you normally do when speaking to an ethnically different person?

12. Were there perceived assumptions that you may have had of the different ethnic group when trying to communication with them? 